Check for updates

Cite this: RSC Adv., 2017, 7, 41190

Received 15th May 2017 Accepted 24th July 2017

DOI: 10.1039/c7ra05479c

rsc.li/rsc-advances

\section{Low-temperature molten-salt synthesis and upconversion of novel hexagonal $\mathrm{NaBiF}_{4}: \mathrm{Er}^{3+} / \mathrm{Yb}^{3+}$ micro-/nanocrystals}

\begin{abstract}
Xinyang Huang, (DD* Liang Jiang, Qiuju Xu, Xiaoxia Li and Aiqun He
A series of $\mathrm{NaBiF}_{4}: \mathrm{Er}^{3+} / \mathrm{Yb}^{3+}$ micro-/nanocrystals were synthesized via the low-temperature molten-salt method in $\mathrm{NH}_{4} \mathrm{NO}_{3}$ flux. The influences of the amount of $\mathrm{NaF}$ and $\mathrm{NH}_{4} \mathrm{NO}_{3}$ flux used, the reaction time and reaction temperature on the crystal phase structure, morphology and size of the resultant samples were systematically investigated. The morphology, size, doped concentrations of $\mathrm{Er}^{3+}$ and $\mathrm{Yb}^{3+}$, pumping power, and temperature dependences of UC emissions were studied in detail under $980 \mathrm{~nm}$ irradiation. The $\mathrm{NaBiF}_{4}: 3 \mathrm{~mol} \% \mathrm{Er}^{3+} / 20 \mathrm{~mol} \% \mathrm{Yb}^{3+}$ crystal exhibits the strongest green UC emission, which was observed under several $\mathrm{mW} 980 \mathrm{~nm}$ excitation at room temperature. The energy transfer between $\mathrm{Bi}^{3+}$ and $\mathrm{Er}^{3+}$ during UC emission process was also discussed at length.
\end{abstract}

\section{Introduction}

In the past decades, lanthanide-doped upconversion (UC) inorganic materials have evoked a tremendous amount of attention to the ongoing research. UC refers to a system sequentially absorbing two or more long-wavelength (lowenergy) photons, combining their energies, and emitting one short-wavelength (high-energy) photon. Compared to semiconductor quantum dots, these UC materials exhibit some advantages of low toxicity, large Stokes shift, sharp emission band, high quantum yield, long lifetime, weak background luminescence, and good resistance to photo-bleaching, blinking and photochemical degradation. ${ }^{1-3}$ Owing to their outstanding properties, they have been proposed for diverse potential applications in photovoltaic, $^{3-5}$ photocatalysis, ${ }^{4,5}$ sensor and biological labels. ${ }^{6-9}$

$\mathrm{Er}^{3+}$, as being an excellent activated ion, can emit different wavelength photons ranging from ultraviolet (UV) through visible (red, blue, green) to near infrared (NIR) light. Unfortunately, $\mathrm{Er}^{3+}$ suffers from inferior absorption near $980 \mathrm{~nm}$ (compared with $\mathrm{Yb}^{3+}$ ), and low $\mathrm{Er}^{3+}$ doping concentration (in the range $0.2-2 \%$ ) to avoid significant concentration-quenching. ${ }^{5-9}$ To enhance UC efficiency, a popular approach is adopted where a sensitizer with a reasonable cross section in NIR region is co-doped due to an efficient energy transfer between the two. $\mathrm{Yb}^{3+}$ has a relatively large absorption cross section $\left(1.2 \times 10^{-20} \mathrm{~cm}^{2}\right)$ compared with that of $\mathrm{Er}^{3+}\left(1.7 \times 10^{-21} \mathrm{~cm}^{2}\right)$ and broad absorption band matching with the emission wavelength of powerful commercial laser diodes, and its ${ }^{2} \mathrm{~F}_{5 / 2}$ excited state resonates well

Institute of Research on the Functional Materials, Jiangxi University of Finance and Economy, Nanchang, Jiangxi 330013, PR China. E-mail: xyhang0202@hotmail.com; Fax: +86-791-83891364; Tel: +86-791-83891364 with the ${ }^{4} \mathrm{I}_{11 / 2}$ excited state of $\mathrm{Er}^{3+}$, thus $\mathrm{Yb}^{3+}$ can significantly improve UC efficiency of $\mathrm{Er}^{3+} \cdot{ }^{10-13}$

It is generally accepted that $\mathrm{Bi}^{3+}$ ions possess some inherent features of non-toxicity, low cost, and large rare-earth ion admittance. From the point of optical physics, $\mathrm{Bi}^{3+}$ ions have $6 \mathrm{~s}^{2}$ electronic configuration $\left({ }^{1} \mathrm{~S}_{0}\right.$ corresponds to the ground state, whereas ${ }^{3} \mathrm{P}_{0},{ }^{3} \mathrm{P}_{1}$ and ${ }^{3} \mathrm{P}_{2}$ are due to three excited states) and a broad absorption and emission band, ${ }^{\mathbf{1 4 - 1 6}}$ which is usually used in downconversion and UC emission system to enhance luminescence. ${ }^{\mathbf{1 6 - 2 1}}$ For example, the $\mathrm{Bi}^{3+}$ ion in hexagonal $\mathrm{NaYF}_{4}$ possesses a broad absorption near $300 \mathrm{~nm}$ and a emission band ranging from 400 to $500 \mathrm{~nm} .^{22}$ The introduction of the optimal $\mathrm{Bi}^{3+}$ can obviously enhance UC emission of hexagonal $\mathrm{NaYF}_{4}$ :$\mathrm{Er}^{3+} / \mathrm{Yb}^{3+}$ materials. ${ }^{21}$ In addition, fluoride compounds possess a host lattice of low phonon energies (less than $350 \mathrm{~cm}^{-1}$ ) causing to decrease nonradiative relaxation and in turn to yield relatively strong UC emission, they have served as very efficient UC matrixes. For instance, $\mathrm{NaREF}_{4}(\mathrm{RE}=\mathrm{Y}, \mathrm{Gd}$ and $\mathrm{Lu})$ is one kind of the efficient NIR-vis UC host materials. ${ }^{23-27}$ Therefore, $\mathrm{Bi}^{3+}$-based fluorides can combine the advantages of both fluorides and $\mathrm{Bi}^{3+}$ ions, they are suggested to be novel UC materials with efficient luminescence and have been attracted more and more attention. ${ }^{28-31}$ As one member of $\mathrm{Bi}^{3+}$-based fluorides, $\mathrm{NaBiF}_{4}$ belongs to the hexagonal system with the space group $P \overline{3}$ and the unit cell parameters: $a=6.144 \AA, c=3.721 \AA$ (ref. 32) and has the same structure as $\mathrm{NaREF}_{4},{ }^{1-3}$ thereby, the addition of $\mathrm{Er}^{3+}$ and $\mathrm{Yb}^{3+}$ can not generate the crystal lattice distortion and exhibits the capacity of heavily rare-earth ion doping. The $\mathrm{Yb}^{3+} / \mathrm{RE}^{3+}(\mathrm{RE}=\mathrm{Er}$, Tm, and $\mathrm{Ho})$ doped hexagonal $\mathrm{NaBiF}_{4}$ nanocrystals has demonstrated to be one potential excellent UC material. $^{31}$

In past several decades, rare-earth doped $\mathrm{NaREF}_{4}$ materials with high dispersability were synthesized in organic solvents by 
hydro(solvo)thermal methods. ${ }^{\mathbf{1 1 1 , 3 3 - 3 5}}$ In contrast with the above methods, the most advantage of low-temperature molten-salt method is an economical mass, convenient, effective, facile and environmental friendly approach. And it is very easy to obtain the materials with clean surface, chemical purification, and few residual impurities below the melting point of the asgrown crystals. Ammonium nitrate $\left(\mathrm{NH}_{4} \mathrm{NO}_{3}\right)$ exhibits some inherent advantages, including abundance in nature, low melting point, and easy deliquescence in water/alcohol causing to easily separate from the flux and the target compound. Thus, this synthetic route has been has been adopted to fabricate hexagonal $\mathrm{NaYF}_{4}: \mathrm{Er}^{3+} / \mathrm{Yb}^{3+}, 36$ tetragonal $\mathrm{LiYF}_{4}: \mathrm{Er}^{3+} / \mathrm{Yb}^{3+},{ }^{37}$ cubic $\mathrm{BaGdF}_{5}: \mathrm{Ce}^{3+} / \mathrm{Er}^{3+} / \mathrm{Yb}^{3+}$ (ref. 38) and monazite $\mathrm{LaPO}_{4}: \mathrm{Eu}^{3+} \cdot{ }^{39}$ Recently, the $\mathrm{Yb}^{3+} / \mathrm{RE}^{3+}(\mathrm{RE}=\mathrm{Er}, \mathrm{Tm}$, and Ho) doped hexagonal $\mathrm{NaBiF}_{4}$ nanocrystals have been fabricated in ethylene glycol at room temperature. ${ }^{31}$ Unfortunately, the degree of the crystalline and their UC emissions need to be further improved. Therefore, here, hexagonal $\mathrm{NaBiF}_{4}: \mathrm{Er}^{3+} / \mathrm{Yb}^{3+}\left(\mathrm{h}-\mathrm{NaBiF}_{4}: \mathrm{Er}^{3+} / \mathrm{Yb}^{3+}\right.$ ) micro-/ nanocrystals will be prepared by the low-temperature moltensalt synthesis in $\mathrm{NH}_{4} \mathrm{NO}_{3}$ flux. In this synthetic route, the phase structure, shape and size of the samples could be highly determined by the intrinsic structure of target compound and the growth surroundings (such as the reaction temperature, the reaction time, and the usage amounts of raw materials and flux). To obtain high-quality $\mathrm{NaBiF}_{4}: \mathrm{Er}^{3+} / \mathrm{Yb}^{3+}$ micro-/nanocrystals, it is very necessary to fastidiously control these parameters. Herein, we will mainly concentrate upon the influence of the usage amount of reaction materials $\mathrm{NaF}$ and flux $\mathrm{NH}_{4} \mathrm{NO}_{3}$, the reaction temperature and the reaction time on the chemical composition, the morphology and size of the resultant products. On this basis, the corresponding UC properties will be investigated and discussed in detail. Finally, the
UC emission dynamics of $\mathrm{h}-\mathrm{NaBiF}_{4}: \mathrm{Er}^{3+} / \mathrm{Yb}^{3+}$ will be studied by the pumping power, and temperature dependences of UC emissions and fluorescence decays.

\section{Experimental}

\subsection{Material preparation}

$\mathrm{NaBiF}_{4}: \mathrm{Er}^{3+} / \mathrm{Yb}^{3+}$ samples were synthesized by the low temperature molten-salt method in $\mathrm{NH}_{4} \mathrm{NO}_{3}$ flux. Reagent-grade $\mathrm{NaF}$, $\mathrm{NH}_{4} \mathrm{NO}_{3}, \mathrm{Bi}\left(\mathrm{NO}_{3}\right)_{3} \cdot 5 \mathrm{H}_{2} \mathrm{O}, \mathrm{Yb}\left(\mathrm{NO}_{3}\right)_{3} \cdot 5 \mathrm{H}_{2} \mathrm{O}$ and $\operatorname{Er}\left(\mathrm{NO}_{3}\right)_{3} \cdot 5 \mathrm{H}_{2} \mathrm{O}$ powders were used to synthesize hexagonal $\mathrm{Er}^{3+} / \mathrm{Yb}^{3+}$-codoped $\mathrm{NaBiF}_{4}$ crystals. All the reagent-grade powders and $\mathrm{NH}_{4} \mathrm{NO}_{3}$ with different usage amounts were mixed well. The mixtures were put into $15 \mathrm{ml}$ capacity crucibles. After the lids were tightly closed, the crucibles were placed in an oven. The sealed tank was heated to different reaction temperature $(160,175,210$ and $250^{\circ} \mathrm{C}$ ), and held for different hours $(0.5,1,2,4,8,12$ and $24 \mathrm{~h})$ in an oven, and then cooled to room temperature naturally. The detailed experimental parameters including the reaction temperature, reaction time, the doping concentration of $\mathrm{Er}^{3+}$ and $\mathrm{Yb}^{3+}$, the NaF usage amount and the usage amount of $\mathrm{NH}_{4} \mathrm{NO}_{3}$ flux were listed in Table 1 . After being washed several times with deionized water and ethanol, the precipitates were dried at $70{ }^{\circ} \mathrm{C}$ for 12 hours in vacuum.

\subsection{Material characterization}

The samples were examined by X-ray diffraction (XRD), transmission electron microscopy (TEM), energy-dispersive X-ray spectroscopy (EDS) and photoluminescence (PL). XRD analyses were carried out on a Bruker D8-Advance diffractometer with graphite-monochromatized $\mathrm{Cu} \mathrm{K} \alpha$ radiation $(40 \mathrm{kV} / 60 \mathrm{~mA}$, graphite monochromator, $\lambda=0.1541 \mathrm{~nm})$. The size,

Table 1 The detailed experimental parameters and crystal phase of the as-obtained samples

\begin{tabular}{|c|c|c|c|c|c|}
\hline Sample & $\begin{array}{l}\mathrm{NaF} / \mathrm{Ln} \\
\text { molar ratio }\end{array}$ & $\begin{array}{l}\mathrm{NH}_{4} \mathrm{NO}_{3} / \\
\mathrm{Ln} \\
\text { molar ratio }\end{array}$ & $\begin{array}{l}\text { Reaction } \\
\text { temperature }\left({ }^{\circ} \mathrm{C}\right)\end{array}$ & $\begin{array}{l}\text { Reaction } \\
\text { time (h) }\end{array}$ & Crystal phase \\
\hline S1 & 3 & 5 & 250 & 24 & $\mathrm{c}-\mathrm{BiF}_{3}+\mathrm{t}-\mathrm{BiOF}$ \\
\hline $\mathrm{S} 2$ & 4 & 5 & 250 & 24 & \\
\hline $\mathrm{S} 3$ & 5 & 5 & 250 & 24 & h-NaBiF 4 \\
\hline $\mathrm{S} 4$ & 6 & 5 & 250 & 24 & h-NaBiF 4 \\
\hline S5 & 8 & 5 & 250 & 24 & h-NaBiF 4 \\
\hline S6 & 5 & 8 & 250 & 24 & h-NaBiF 4 \\
\hline S7 & 5 & 10 & 250 & 24 & h-NaBiF 4 \\
\hline S9 & 6 & 8 & 250 & 24 & $\mathrm{~h}-\mathrm{NaBiF}_{4}$ \\
\hline S10 & 6 & 10 & 250 & 24 & h-NaBiF 4 \\
\hline S11 & 8 & 8 & 250 & 24 & h-NaBiF 4 \\
\hline S12 & 8 & 10 & 250 & 24 & h-NaBiF 4 \\
\hline S13 & 5 & 5 & 210 & 24 & h-NaBiF 4 \\
\hline S14 & 5 & 5 & 180 & 24 & $\mathrm{~h}-\mathrm{NaBiF}_{4}+\mathrm{c}-\mathrm{BiF}_{3}+\mathrm{t}-\mathrm{BiOF}$ \\
\hline S15 & 5 & 5 & 160 & 24 & $\mathrm{~m}-\mathrm{NH}_{4} \mathrm{BiF}_{4}+\mathrm{c}-\mathrm{BiF}_{3}+\mathrm{t}-\mathrm{BiOF}$ \\
\hline S16 & 3 & 5 & 250 & 12 & $\mathrm{~h}-\mathrm{NaBiF}_{4}$ \\
\hline S17 & 3 & 5 & 250 & 8 & $\mathrm{~h}-\mathrm{NaBiF}_{4}$ \\
\hline S18 & 3 & 5 & 250 & 4 & $\mathrm{~h}-\mathrm{NaBiF}_{4}$ \\
\hline S19 & 3 & 5 & 250 & 2 & $\mathrm{~h}-\mathrm{NaBiF}_{4}$ \\
\hline S20 & 3 & 5 & 250 & 1 & $\mathrm{~h}-\mathrm{NaBiF}_{4} \mathrm{t}-\mathrm{BiOF}$ \\
\hline S21 & 3 & 5 & 250 & 0.5 & $\mathrm{~h}-\mathrm{NaBiF}_{4} \mathrm{t}-\mathrm{BiOF}$ \\
\hline
\end{tabular}


morphology and chemical compositions of products were determined by a transmission electron microscopy (TEM, JEOL2010) operating at $200 \mathrm{kV}$ and a JSM 6700F scanning electron microscope (SEM) equipped with the energy dispersive $\mathrm{X}$-ray spectrum (EDS). Structural information of the nanocrystals was measured by a high-resolution transmission electron microscopy (HRTEM).

Downconversion (DC) luminescence spectra were performed using an Edinburgh Instruments FLS920 fluorescence spectrometer equipped with both continuous $(450 \mathrm{~W})$ and pulsed xenon lamps. UC emission spectra were carried out upon $976 \mathrm{~nm}$ excitation with a pump power of $\sim 200 \mathrm{~mW}$ (power density $\sim 20 \mathrm{~W} \mathrm{~cm}^{-2}$ ), provided by a mode-locked picosecond Ti:sapphire laser $(700-1000 \mathrm{~nm}$, pulse width $\leq$ 1.5 ps, Tsunami, Spectra-Physics). The measurements were repeated in an integrating sphere in order to reduce the effect of the scattering on the UC properties. Power-dependence of UC emissions of $\mathrm{Er}^{3+}$ was studied upon excitation by a powercontrollable $976 \mathrm{~nm}$ diode laser (DPL-II, Module HTL98M10) with two emission monochromators to record the emission spectra in the wavelength range of 200-850 $\mathrm{nm}$ (with a Hamamatsu R928 photomultiplier tube). Its maximum power output is $5 \mathrm{~W}$. To eliminate the noise from tunable Ti:sapphire laser, $980 \mathrm{~nm} \mathrm{LD}$, and both continuous $(450 \mathrm{~W})$ and pulsed xenon lamps, different filters were kept in front of the detector. The emission monochromator's slits were set as small as possible to maximize the instrumental resolution. The best wavelength resolution was $0.05 \mathrm{~nm}$. The line intensities and positions of the measured spectra were calibrated according to the FLS920 correction curve and standard mercury lamp. All the spectra were measured at room temperature and under identical conditions for each serial test. Luminescence decays were recorded using a customized UV to mid-infrared steady-state and phosphorescence lifetime spectrometer (FSP920-C, Edinburgh) equipped with a digital oscilloscope (TDS3052B, Tektronix) and a tunable mid-band OPO pulse laser as the excitation source $(410-2400 \mathrm{~nm}$, $10 \mathrm{~Hz}$, pulse width $\leq 5 \mathrm{~ns}$, Vibrant 355II, OPOTEK). For the low-temperature measurements, the samples were mounted on a closed-cycle cryostat (10-350 K, DE202, Advanced Research Systems).

\section{Results and discussion}

\subsection{Phase structure}

When the molar ratio of $\mathrm{NaF}$ to $\mathrm{Ln}\left(\mathrm{NO}_{3}\right)_{3}$ (hereinafter to be referred as $\mathrm{NaF} / \mathrm{Ln}$ ) was 3 , the resultant product consists of cubic $\mathrm{BiF}_{3}\left(\mathrm{c}-\mathrm{BiF}_{3}\right)$ (JCPDS no. 74-0144) and tetragonal BiOF (tBiOF) (JCPDS no. 86-1478) (Fig. 1a) and the XRD peaks due to hexagonal $\mathrm{NaBiF}_{4}$ (h-NaBiF 4 ) (JCPDS no. 041-0796) were not observed. When the NaF/Ln molar ratio increased to $4, \mathrm{~h}-\mathrm{NaBiF}_{4}$ phase appeared and played a predominant role (Fig. 1a), and yet a small quantity of c- $\mathrm{BiF}_{3}$ could be still detected. As the $\mathrm{NaF} / \mathrm{Ln}$ molar ratio increased to 5 , the diffraction peaks due to $\mathrm{c}-\mathrm{BiF}_{3}$ disappeared and those due to t-BiOF continued to weaken. The further increasing $\mathrm{NaF} / \mathrm{Ln}$ molar ratio to 8 , the diffraction peaks due to the t-BiOF vanished, all the diffraction peaks were in good agreement with those of pure $\mathrm{h}-\mathrm{NaBiF}_{4}$ and no trace of characteristic peaks for other impurity phases was observed, implying that the samples obtained have the same crystallographic structure as pure h-NaBiF 4 crystal. Thus, the h-NaBiF can be synthesized at $\mathrm{NaF} / \mathrm{Ln}$ molar ratio above 5 , and the $\mathrm{NH}_{4} \mathrm{NO}_{3}$ molten solution system can be developed to prepare the h- $-\mathrm{NaBiF}_{4}$ materials.

From Fig. 1b, it can be seen that the variance of the reaction temperature also highly affects the phase structure of the products. For the sample obtained at 210 and $250{ }^{\circ} \mathrm{C}$ for 12 hours, only h-NaBiF ${ }_{4}$ (JCPDS no. 041-0796) was obtained. When the reaction temperature decreased to $175{ }^{\circ} \mathrm{C}$, the t-BiOF and monoclinic $\mathrm{NH}_{4} \mathrm{BiF}_{4}\left(\mathrm{~m}-\mathrm{NH}_{4} \mathrm{BiF}_{4}\right)$ (JCPDS no. 041-0796) were formed. With the reaction temperature further decreasing to $160{ }^{\circ} \mathrm{C}$, the $\mathrm{m}-\mathrm{NH}_{4} \mathrm{BiF}_{4}$ became more and more and played a predominant role while the amount of $\mathrm{h}-\mathrm{NaBiF}_{4}$ significantly decreased. As is known, the thermodynamic growth regime is highly dependent upon a sufficient supply of thermal energy, and the crystal with the most stable structure preferential grows. ${ }^{40}$ Since $\mathrm{h}-\mathrm{NaBiF}_{4}$ is thermodynamically more stable than $\mathrm{m}-\mathrm{NH}_{4} \mathrm{BiF}_{4}$ and $\mathrm{t}-\mathrm{BiOF}, \mathrm{m}-\mathrm{NH}_{4} \mathrm{BiF}_{4}$ and t-BiOF are susceptible to transform to $\mathrm{h}-\mathrm{NaBiF}_{4}$. The energy barrier hinders the formation of the $\mathrm{h}-\mathrm{NaBiF}_{4}$, a sufficient supply of thermal energy must be required to surmount this energy barrier to adjust the environment of $\mathrm{Bi}^{3+}\left(\mathrm{Er}^{3+}\right.$ and $\left.\mathrm{Yb}^{3+}\right)$ and $\mathrm{Na}^{+}$occupation sites. ${ }^{41}$ Therefore in this thermal system $\mathrm{m}-\mathrm{NH}_{4} \mathrm{BiF}_{4}$ and $\mathrm{t}$-BiOF can be formed at low temperature, relatively high reaction temperature is more favorable for this transformation $\left(\mathrm{m}^{-} \mathrm{NH}_{4} \mathrm{BiF}_{4} \rightarrow\right.$ $\mathrm{NaBiF}_{4}$ and t-BiOF $\rightarrow$ h-NaBiF 4 ) in the molten salt process and the pure $\mathrm{h}-\mathrm{NaBiF}_{4}$ crystals can be synthesized at the reaction temperature of $210{ }^{\circ} \mathrm{C}$ and above.

To study the impact of the reaction time on the phase structure and the growth mechanism, the XRD patterns of the products prepared for different reaction times of $0.5,1,2,4,8$, 12 and $24 \mathrm{~h}$, as shown in Fig. 1c, indicates that the crystal phase of the samples is strongly dependent on the reaction time. When the reaction time was $0.5 \mathrm{~h}$, a great amount of $\mathrm{h}-\mathrm{NaBiF}_{4}$ and a small amount of t-BiOF were also observed and $\mathrm{m}$ $\mathrm{NH}_{4} \mathrm{BiF}_{4}$ (JCPDS no. 041-0796) was hardly detected. The t-BiOF became less and less with the elongation of the reaction time from 0.5 hour to 4 hours and disappeared as the reaction time extended to 8 and 12 hours. It is demonstrated that the longer reaction time is also beneficial to transform from t-BiOF to $\mathrm{h}$ $\mathrm{NaBiF}_{4}$ and the pure $\mathrm{h}-\mathrm{NaBiF}_{4}$ crystals can be also obtained when the reaction time exceeds $8 \mathrm{~h}$. Moreover, in comparison to (101) and (201) XRD peaks owing to he hexagonal $\mathrm{NaBiF}_{4}$, the (110) and (110) XRD peaks becomes stronger with the extension of the reaction time, implying that the [0001] direction is the preferred direction of crystal growth.

XRD patterns of the products with different concentrations of $\mathrm{Er}^{3+}$ or $\mathrm{Yb}^{3+}$ for 24 hours are shown in Fig. 1d, e and $\mathrm{f}$ with $\mathrm{h}$ $\mathrm{NaBiF}_{4}$ standard card (no. 41-0796). All the XRD peaks are in good agreement with those of the $\mathrm{h}-\mathrm{NaBiF}_{4}$, showing that all the products have the same crystal structure as pure $\mathrm{h}-\mathrm{NaBiF}_{4}$. Because of the replacement of $\mathrm{Bi}^{3+}$ with smaller $\mathrm{Er}^{3+}$ and $\mathrm{Yb}^{3+}$ ions in the host lattice, the diffraction peaks shift slightly to higher angle side as a result of the shrinkage of the unit-cell volume. 

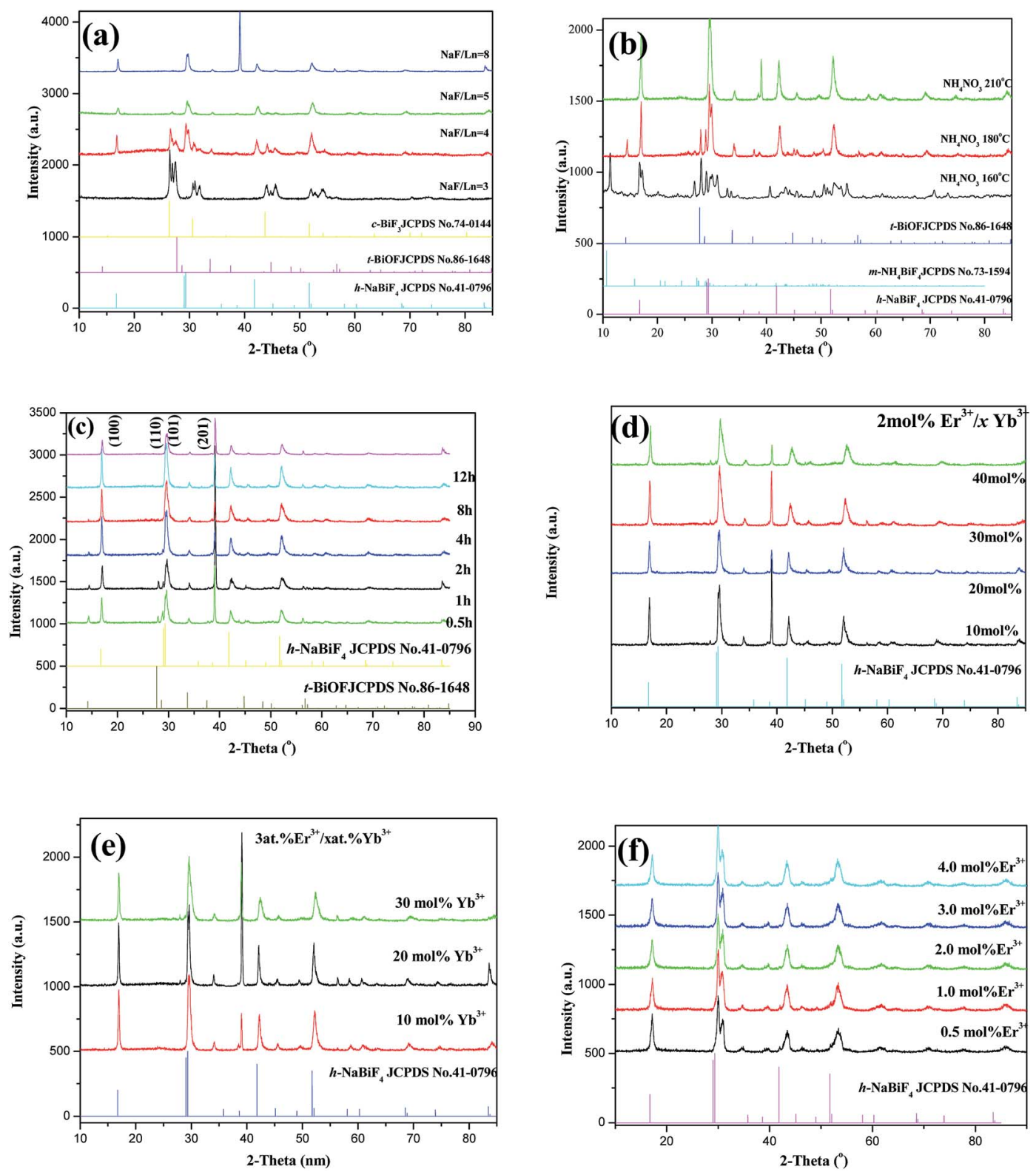

Fig. 1 The XRD patterns of the samples prepared under different conditions. (a) Different molar ratios of NaF/Ln; (b) different temperatures; (c) different times; (d) doped with 2 mol\% $\mathrm{Er}^{3+}$ and different $\mathrm{Yb}^{3+}$ concentrations; (e) doped with 3 mol\% $\mathrm{Er}^{3+}$ and different $\mathrm{Yb}^{3+}$ concentrations; (f) doped with $20 \mathrm{~mol} \% \mathrm{Yb}^{3+}$ and different $\mathrm{Er}^{3+}$ concentrations.

\subsection{Morphology}

Fig. 2-5 illustrate some representative SEM images of h$\mathrm{NaBiF}_{4}: \mathrm{Er}^{3+} / \mathrm{Yb}^{3+}$ prepared under different reaction conditions, as listed in Table 1. When the molar ratio of $\mathrm{NaF} / \mathrm{Ln}$ was 3.0, the corresponding sample is composed of a large number of tiny nanoparticles attached to the surface of large polyhedral particles with size of $c a .0 .6 \mu \mathrm{m}$. The product prepared at the NaF/Ln molar ratio of 4 mainly consists of many prismatic microrods with $4-5 \mu \mathrm{m}$ in length and $c a .0 .8 \mu \mathrm{m}$ in diameter. Their lateral surfaces (Fig. 2a and 3a) are covered with a layer of minute irregular nanoparticles while their end planes are coarse, concave and irregular. When the molar ratio of NaF/Ln was increased to 5.0, the product maintains rod-like morphology and becomes even uniform. Their sizes and end planes keep nearly unchanged, whereas their lateral surfaces become relatively smooth and have some fine slit along the rods. With the increasing $\mathrm{NaF} / \mathrm{Ln}$ molar ratio to 6.0 , the morphology of the product still exhibits prismatic microrods, whenas their length and diameter slightly decrease to $3-4 \mu \mathrm{m}$ and $c a .0 .8 \mu \mathrm{m}$, respectively. Some small holes appear on their surfaces. Further increasing $\mathrm{NaF} / \mathrm{Ln}$ molar ratio to 8.0 deduces the prisms incomplete and their length and diameter are 3-5 $\mu \mathrm{m}$ and 0.6 $\mu \mathrm{m}$, respectively. There are a great number of relatively large holes on their side surfaces of these prisms.

To study the impact of the variation of the amount of flux $\mathrm{NH}_{4} \mathrm{NO}_{3}$ upon the morphology and size of the products, the 

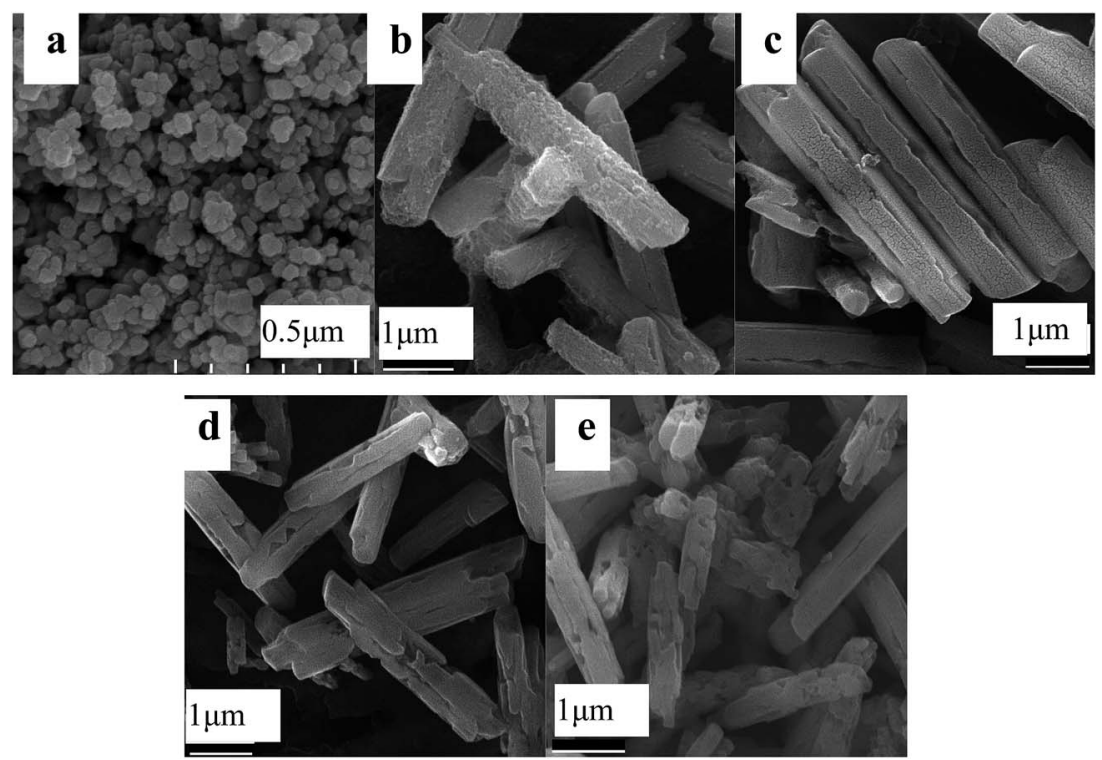

Fig. 2 Representative SEM images of the as-obtained products at $250^{\circ} \mathrm{C}$ for 24 hours with the $\mathrm{NH}_{4} \mathrm{NO}_{3} / \mathrm{Ln}$ molar ratio of 5 , and different NaF/Ln molar ratios of 3 (a), 4 (b), 5 (c), 6 (d) and 8 (e).

SEM images of the samples with different $\mathrm{NH}_{4} \mathrm{NO}_{3} / \mathrm{Ln}$ molar ratios were shown in Fig. 3. The $\mathrm{NH}_{4} \mathrm{NO}_{3}$ usage amount produces a great influence upon their sizes. When the NaF/Ln molar ratio was fixed to be 5 and 6 , the molar ratio of $\mathrm{NH}_{4} \mathrm{NO}_{3} / \mathrm{Ln}$ increased to 8 and 10 , the resultant products still maintain prism-like morphology. Meanwhile, their diameters also nearly stay at the same level (ca. $0.8 \mu \mathrm{m})$, and the mean lengths decrease to $c a$. $3.0 \mu \mathrm{m}$. For the $\mathrm{NaF} / \mathrm{Ln}$ molar ratio of 8 , the $\mathrm{NH}_{4} \mathrm{NO}_{3} / \mathrm{Ln}$ molar ratio enhances from 5 through 8 to 10 , the diameters of these rods also keep almost invariable ( $c a$. $0.5 \mu \mathrm{m})$, the lengths experience a significant downward from $3.0 \mu \mathrm{m}$ through $2.0 \mu \mathrm{m}$ to $1.0 \mu \mathrm{m}$. That is to say, the larger $\mathrm{NH}_{4} \mathrm{NO}_{3} / \mathrm{Ln}$ molar ratio is, the smaller the aspect ratio length/ diameter becomes.
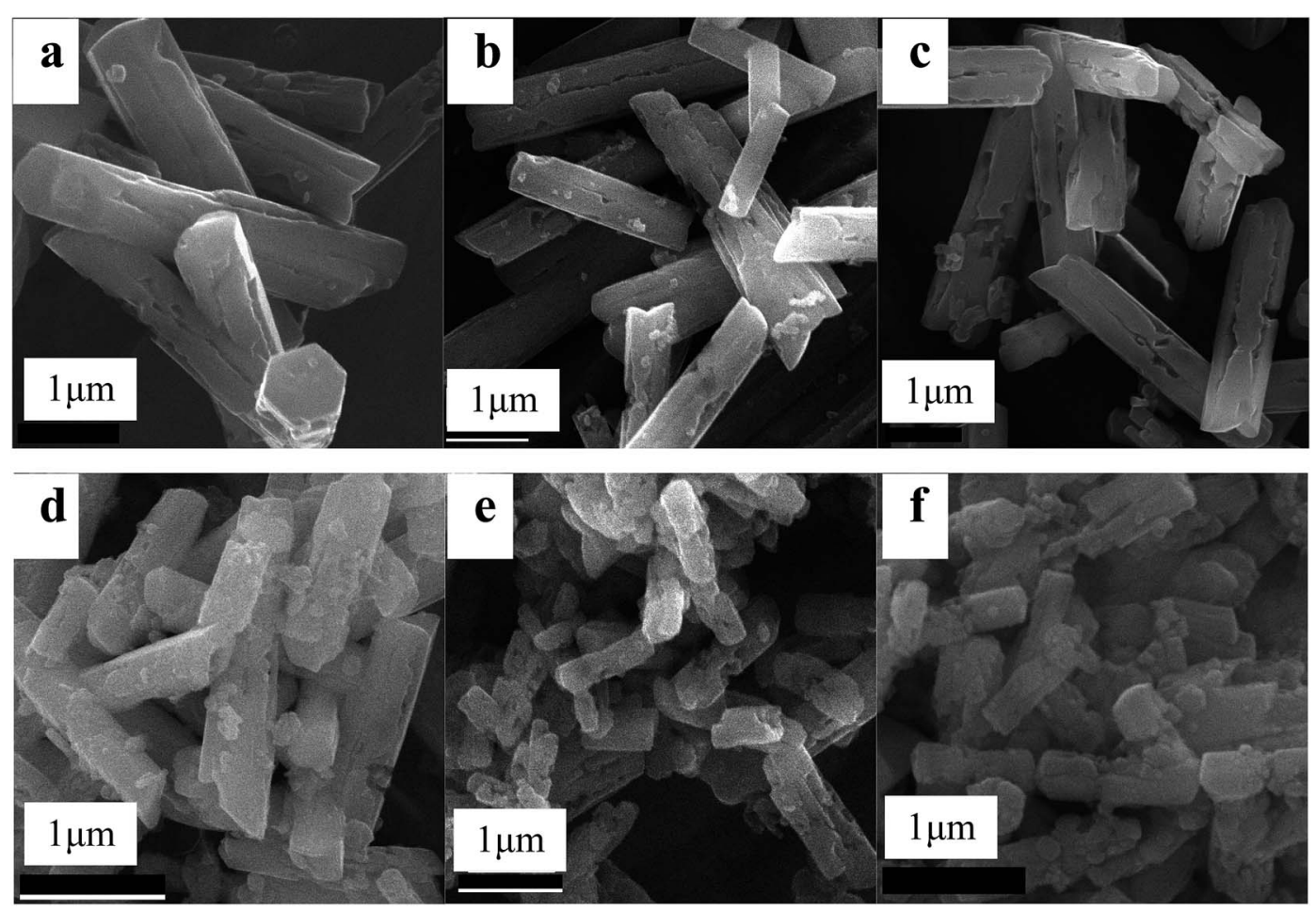

Fig. 3 Representative SEM images of the as-obtained products at $210{ }^{\circ} \mathrm{C}$ for 24 hours with the $\mathrm{NaF} / \mathrm{NH}_{4} \mathrm{NO}_{3} / \mathrm{Ln}$ molar ratio of $5 / 8 / 1$ (a), $5 / 10 / 1$ (b), 6/8/1 (c), 6/10/1 (d), 8/8/1 (e) and 8/10/1 (f). 


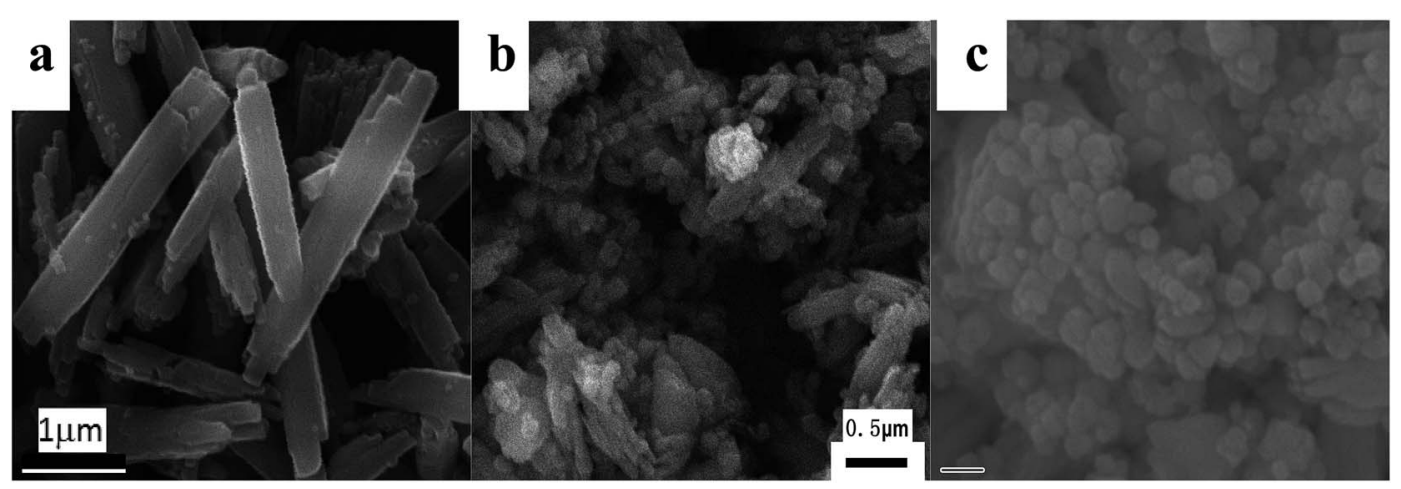

Fig. 4 Representative SEM images of the as-obtained products under for 24 hours with the $\mathrm{NH}_{4} \mathrm{~F} / \mathrm{Ln}$ molar ratio of 5 and $\mathrm{NH}_{4} \mathrm{NO}_{3} / \mathrm{Ln}$ molar ratios of 8 at reaction temperature of $210^{\circ} \mathrm{C}$ (a), $180^{\circ} \mathrm{C}$ (b) and $160^{\circ} \mathrm{C}$ (c).
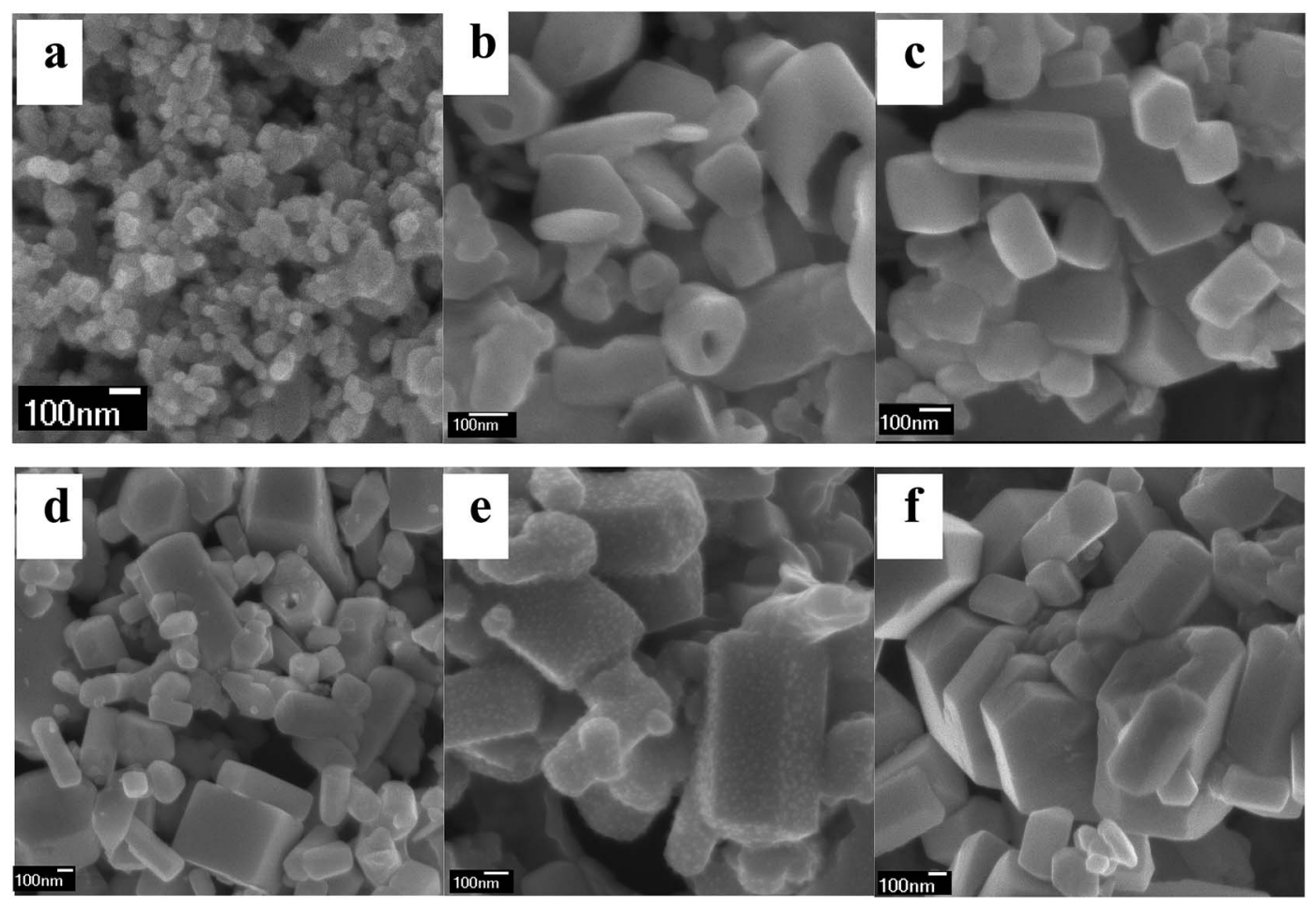

Fig. 5 Representative SEM images of the as-obtained products under at $250{ }^{\circ} \mathrm{C}$ for $24 \mathrm{~h}$ with the $\mathrm{NH}_{4} \mathrm{~F} / \mathrm{Ln}$ molar ratio of 5 and $\mathrm{NH}_{4} \mathrm{NO}_{3} / \mathrm{Ln}$ molar ratios of 8 for the reaction time of $0.5 \mathrm{~h} \mathrm{(a),} 1 \mathrm{~h} \mathrm{(b),} 2 \mathrm{~h} \mathrm{(c),} 4 \mathrm{~h} \mathrm{(d),} 8 \mathrm{~h} \mathrm{(e)} \mathrm{and} 12 \mathrm{~h}(\mathrm{f})$.

To elucidate the effect of the reaction temperature on the morphology the detailed temperature-dependent experiments were carried out under the similar reaction conditions. When the reaction temperature decreases from $250{ }^{\circ} \mathrm{C}$ to $210{ }^{\circ} \mathrm{C}$, the corresponding sample takes on prismatic shape with the length of $c a$. 2.0-3.0 $\mu \mathrm{m}$, the diameter of $c a .0 .3-0.5 \mu \mathrm{m}$ and irregular end planes (Fig. 4a). In comparison with S3, the length and diameter simultaneously have a downward trend. Further decreasing reaction temperature to $180^{\circ} \mathrm{C}$ deduces the prismatic rods disappear, and some tiny nanoparticles aggregate together into the prismatic embryonic form (Fig. 4b). When the reaction temperature is $160{ }^{\circ} \mathrm{C}$, the prismatic embryonic form vanish, a great number of tiny nanoparticles have come into being (Fig. 4c).
To shed light on the morphology evolution of $\mathrm{h}-\mathrm{NaBiF}_{4}$ crystal, taking S3 as an example, the morphologies of the intermediates at different growth stages are shown in Fig. 5 and 6. The intermediates exhibit different morphologies at different reaction times. The reaction treatment for 0.5 hour leads to the formation of small hexagonal prisms with average sizes of 10$50 \mathrm{~nm}$ in length and 20-50 nm in diameter (Fig. 5a and 6a). The high-magnification TEM image indicates that the fringe distance ( $d$-spacing) is $0.311 \mathrm{~nm}$ (Fig. $6 \mathrm{~b})$, corresponding to the distance between neighboring (110) planes of $\mathrm{h}-\mathrm{NaBiF}_{4}$ (JCPDS no. 041-0796). The selected area electron diffraction (SAED) pattern, as shown in Fig. 6c, shows the diffraction rings corresponding to (110), (111), (210), (102) and (310) planes of h- 

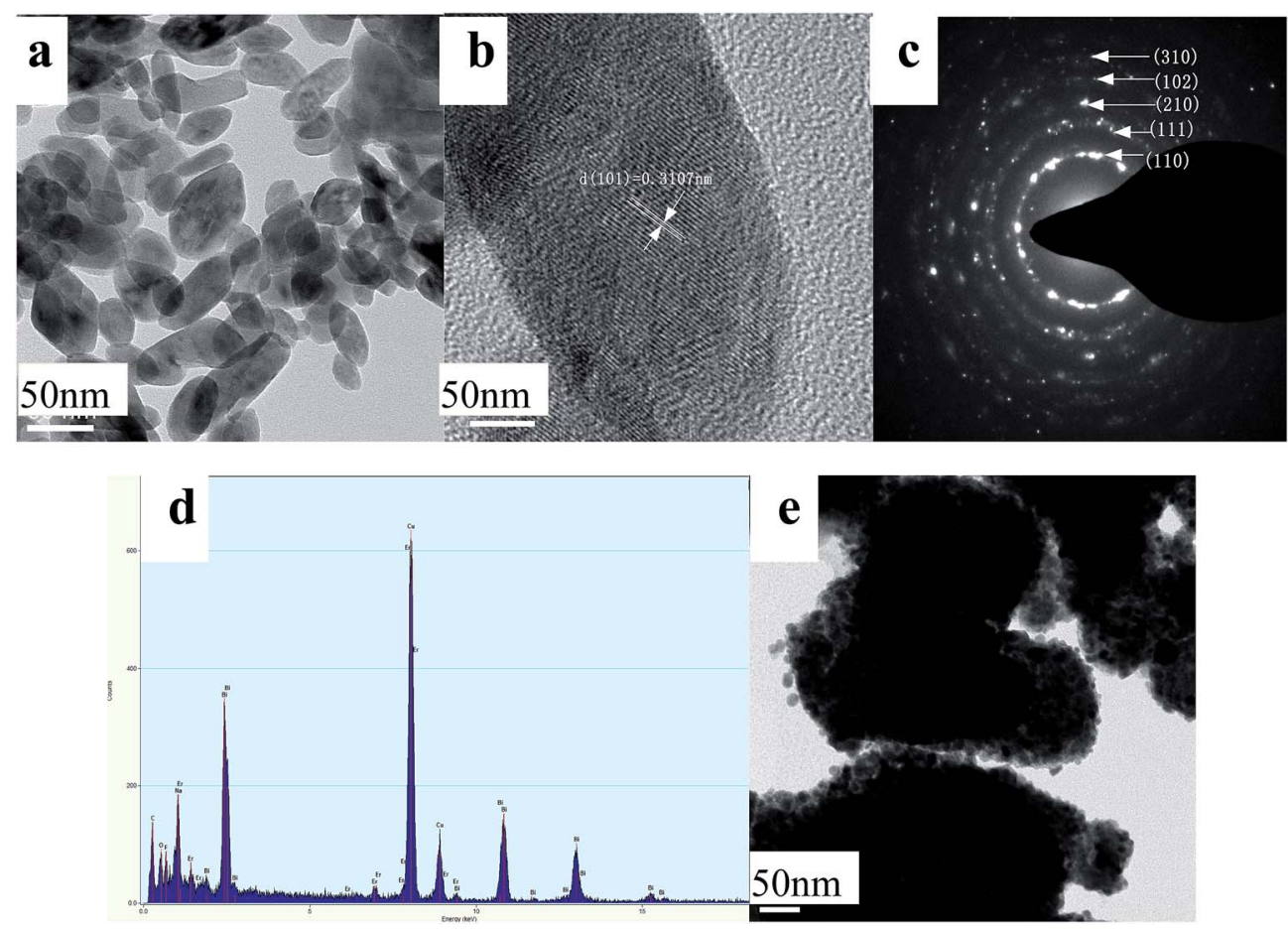

Fig. 6 High-magnification TEM image (a), high-resolution TEM image (b), SAED pattern (c); and EDS spectra (d) of as-prepared NaBiF 43 mol\%

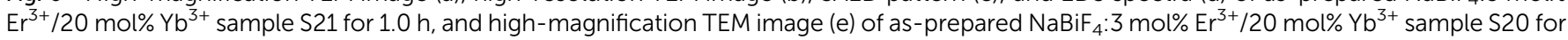
$1.0 \mathrm{~h}$.

$\mathrm{NaBiF}_{4}$. The compositional analysis by EDS pattern spectrum (as shown in Fig. 6d) reveals that the sample is composed of Er, $\mathrm{Yb}, \mathrm{Bi}, \mathrm{Na}$ and $\mathrm{F}$ elements. When the reaction time was increased to $1.0 \mathrm{~h}$, some short and imperfect hexagonal prismatic particles are formed (Fig. 5b). TEM image reveals that these prismatic products are actually polycrystalline, constructed by small particles (Fig. 6e). The holding time of $2.0 \mathrm{~h}$ reduced the these short and imperfect hexagonal prisms to evolve into the regular ones with the length of $200-500 \mathrm{~nm}$ and the diameter of 150-200 $\mathrm{nm}$ and convex end planes (Fig. 5c). When the reaction time was extended to 4 and 8 , the hexagonal prisms continue to grow large while the small particles become less and less (Fig. 5d and e). As the reaction time elongated to $12 \mathrm{~h}$, most of small nanoparticles disappeared and transformed to the hexagonal prismatic rods or plates (Fig. 5f). When the reaction time further extended to $24 \mathrm{~h}$, these irregular nanoparticles depleted and converted to the hexagonal prismatic rods or plates (Fig. 2c). The above results reveal that the rod-like particles undergo dissolution-recrystallization transformation in order to minimize the surface energy of the system, and the $\mathrm{h}-\mathrm{NaBiF}_{4}$ prisms grow along $c$-axis direction at the consumption of smaller nanoparticles by Ostwald ripening process. ${ }^{42}$

\subsection{Formation mechanism}

Herein we have experimentally and independently study the impacts of (1) the reaction time, (2) the reaction temperature, (3) the usage amount of $\mathrm{NaF}(4)$ the usage amount of $\mathrm{NH}_{4} \mathrm{NO}_{3}$ flux upon the resultant morphology and chemical composition.
Based on the above results, a possible phase and morphology evolution mechanism is described as follows.

At the beginning, $\mathrm{Ln}\left(\mathrm{NO}_{3}\right)_{3} \cdot 5 \mathrm{H}_{2} \mathrm{O}(\mathrm{Ln}=\mathrm{Bi}, \mathrm{Yb}$ and $\mathrm{Er})$ and $\mathrm{NaF}$ are mixed with the desired amount of $\mathrm{NH}_{4} \mathrm{NO}_{3}$ salts to form a precursor, which then is reacted above the melting point to provide a fluid phase. Since the melting point of $\mathrm{NH}_{4} \mathrm{NO}_{3}$, $\mathrm{Bi}\left(\mathrm{NO}_{3}\right)_{3} \cdot 5 \mathrm{H}_{2} \mathrm{O}, \mathrm{Yb}\left(\mathrm{NO}_{3}\right)_{3} \cdot 5 \mathrm{H}_{2} \mathrm{O}$ and $\mathrm{Er}\left(\mathrm{NO}_{3}\right)_{3} \cdot 5 \mathrm{H}_{2} \mathrm{O}$ is less than $100{ }^{\circ} \mathrm{C}$, they quickly melt, dissociate and form $\mathrm{Bi}^{3+}, \mathrm{Yb}^{3+}, \mathrm{Er}^{3+}$, $\mathrm{NH}_{4}{ }^{+}$and $\mathrm{NO}_{3}{ }^{-}$ions during the heat-up process, whereas too high melting point of $\mathrm{NaF}\left(\mathrm{ca} .993{ }^{\circ} \mathrm{C}\right)$ cannot melt in such low experimental temperature, howbeit $\mathrm{NaF}$ can be partly dissolved to form $\mathrm{Na}^{+}$and $\mathrm{F}^{-}$ions due to the existence of crystalliferous water. In addition, some $\mathrm{Bi}^{3+}$ ions tend to experience a hydrolysis process and generate $\mathrm{BiO}^{+}$ions during warming-up process.

When the usage amount of $\mathrm{F}^{-}$is beyond the stoichiometric ratio of $\mathrm{h}-\mathrm{NaBiF}_{4}, \mathrm{Na}^{+}, \mathrm{Ln}^{3+}(\mathrm{Ln}=\mathrm{Bi}, \mathrm{Yb}, \mathrm{Er})$ and $\mathrm{NH}_{4}{ }^{+}$ions in the molten salt interact with $\mathrm{F}^{-}$to generate $\mathrm{m}^{-} \mathrm{NH}_{4} \mathrm{BiF}_{4}$ and $\mathrm{h}$ $\mathrm{NaBiF}_{4}$ small nuclei. If the number of $\mathrm{F}^{-}$ions can not exceed this ratio, the $\mathrm{m}-\mathrm{NH}_{4} \mathrm{BiF}_{4}$ and $\mathrm{c}-\mathrm{BiF}_{3}$ take precedence to produce in this molten-salt system. Additionally, those $\mathrm{BiO}^{+}$ions react with $\mathrm{F}^{-}$ions and produce $\mathrm{t}$-BiOF small nuclei. In thermodynamics, $\mathrm{m}-\mathrm{NH}_{4} \mathrm{BiF}_{4}$ and t-BiOF are lower than $\mathrm{h}-\mathrm{NaBiF}_{4}$ and c$\mathrm{BiF}_{3}$, and susceptible to evolve inevitably to h-NaBiF 4 and c- $-\mathrm{BiF}_{3}$ seed through dissolution-renucleation process. These nuclei quickly aggregate together and grown into t-BiOF and h-NaBiF crystals. As the reaction temperature enhances and reaction time extends, the rate of transformation from $\mathrm{m}-\mathrm{NH}_{4} \mathrm{BiF}_{4}$ and tBiOF to h-NaBiF $F_{4}$ becomes larger, more $\mathrm{m}^{-\mathrm{NH}_{4}} \mathrm{BiF}_{4}$ and t-BiOF convert to $\mathrm{h}-\mathrm{NaBiF}_{4}$ by dissolution-recrystallization process. 
On the basis of the general theory of crystal growth, the growth crystal is relevant to the relative growth rate of different crystal faces. The different crystal rates give rise to diverse appearance of the crystalline. Since h- $\mathrm{NaBiF}_{4}$ micro-/nanocrystals have a hexagonal shape, their surfaces are typical (001) top/bottom planes and six prismatic side planes of the energetically equivalent (100) family. In this molten salt system, the growth rate on the $c$-axis in the crystal growth process is quicker than that on the directions perpendicular to $c$-axis, thereby the sample takes on the hexagonal prism. At the same time, the selective adhesion of some simple ions such as $\mathrm{NH}_{4}{ }^{+}$ ions and $\mathrm{Na}^{+}$ions on some specific crystalline planes can change the epitaxial growth rate of different crystallographic direction. ${ }^{38}$ In our experimental surrounding, $\mathrm{NH}_{4}{ }^{+}$or $\mathrm{Na}^{+}$ions preferentially adsorb the (001) crystal plane and thereby remarkably prohibit the $c$-axis (i.e. [001]) directed growth, there is a tendency to shorten the length of prism. The observation of the concave structure at top/bottom facets suggests that the growth rate of the prismatic side facets is little faster than that of the top/bottom facets. These prism-like crystals exhibit the presence of some defects (such as holes and linear slits) on their side surfaces of these prisms, which may be reflected on the preferential 2D-nucleation at the border of the growing face. This behavior can be resulted form the morphological instability generated by the competition between the supersaturation (destabilizing factor) and the surface tension (stabilizing factor). ${ }^{43,44}$

\subsection{Upconversion emission}

To study the effects of $\mathrm{Er}^{3+}$ and $\mathrm{Yb}^{3+}$ concentrations on the UC properties of $\mathrm{h}-\mathrm{NaBiF}_{4}: \mathrm{Er}^{3+} / \mathrm{Yb}^{3+}$ products, Fig. 7 depicts the room temperature UC emission spectra of h- $-\mathrm{NaBiF}_{4}: \mathrm{Er}^{3+} / \mathrm{Yb}^{3+}$ samples with different doping concentrations upon $980 \mathrm{~nm}$ excitation. The strong green UC emission band is observed in the region of 512-573 nm, attributed to the ${ }^{2} \mathrm{H}_{11 / 2} /{ }^{4} \mathrm{~S}_{3 / 2} \rightarrow{ }^{4} \mathrm{I}_{15 / 2}$ transitions of $\mathrm{Er}^{3+}$. The red UC emission between 630-700 nm belongs to ${ }^{4} \mathrm{~F}_{9 / 2} \rightarrow{ }^{4} \mathrm{I}_{15 / 2}$ transition of $\mathrm{Er}^{3+}$. It is striking that the predominant green emission is much stronger than the red emission. Thus, it can emit intense green light with high purity. Besides green and red UC emission, other weak UC emissions at $370-390,400-428$, and $445-460 \mathrm{~nm}$, stem from the ${ }^{4} \mathrm{G}_{11 / 2},{ }^{2} \mathrm{H}_{9 / 2}$, ${ }^{4} \mathrm{~F}_{3 / 2}$ and ${ }^{4} \mathrm{~F}_{5 / 2}$ states to the ${ }^{4} \mathrm{I}_{15 / 2}$ ground state of $\mathrm{Er}^{3+},{ }^{3-12}$ respectively. The UC emission in the range between 485 and $505 \mathrm{~nm}$ is attributed to the overlap of the cooperative UC of $\mathrm{Yb}^{3+},{ }^{45-47}{ }^{4} \mathrm{~F}_{72}{ }^{4} \mathrm{I}_{15 / 2}$ transition of $\mathrm{Er}^{3+}$ (ref. 9-12) and the ${ }^{3} \mathrm{P}_{1}-{ }^{1} \mathrm{~S}_{0}$ transition of $\mathrm{Bi}^{3+}$ ion ${ }^{14,15}$ (see Fig. 7a). It is clearly seen from Fig. 7a and $\mathrm{b}$ that the UC emission is strongly dependent upon the concentration of $\mathrm{Er}^{3+}$ and $\mathrm{Yb}^{3+}$ ions. In the samples with the constant $\mathrm{Er}^{3+}$ concentration ( $2 \mathrm{~mol} \%$ and $3 \mathrm{~mol} \%$ ) the UC emission intensities except ${ }^{4} \mathrm{~F}_{7 / 2}-{ }^{4} \mathrm{I}_{15 / 2}$ UC emission increase as the $\mathrm{Yb}^{3+}$ concentration increases from $10 \mathrm{~mol} \%$ to $20 \mathrm{~mol} \%$, and the maximum UC emission intensity appears at $20 \mathrm{~mol} \%$ $\mathrm{Yb}^{3+}$ doping concentration. Then further increasing $\mathrm{Yb}^{3+}$ doping concentration (such as $30 \mathrm{~mol} \%, 40 \mathrm{~mol} \%$ ) deduces the
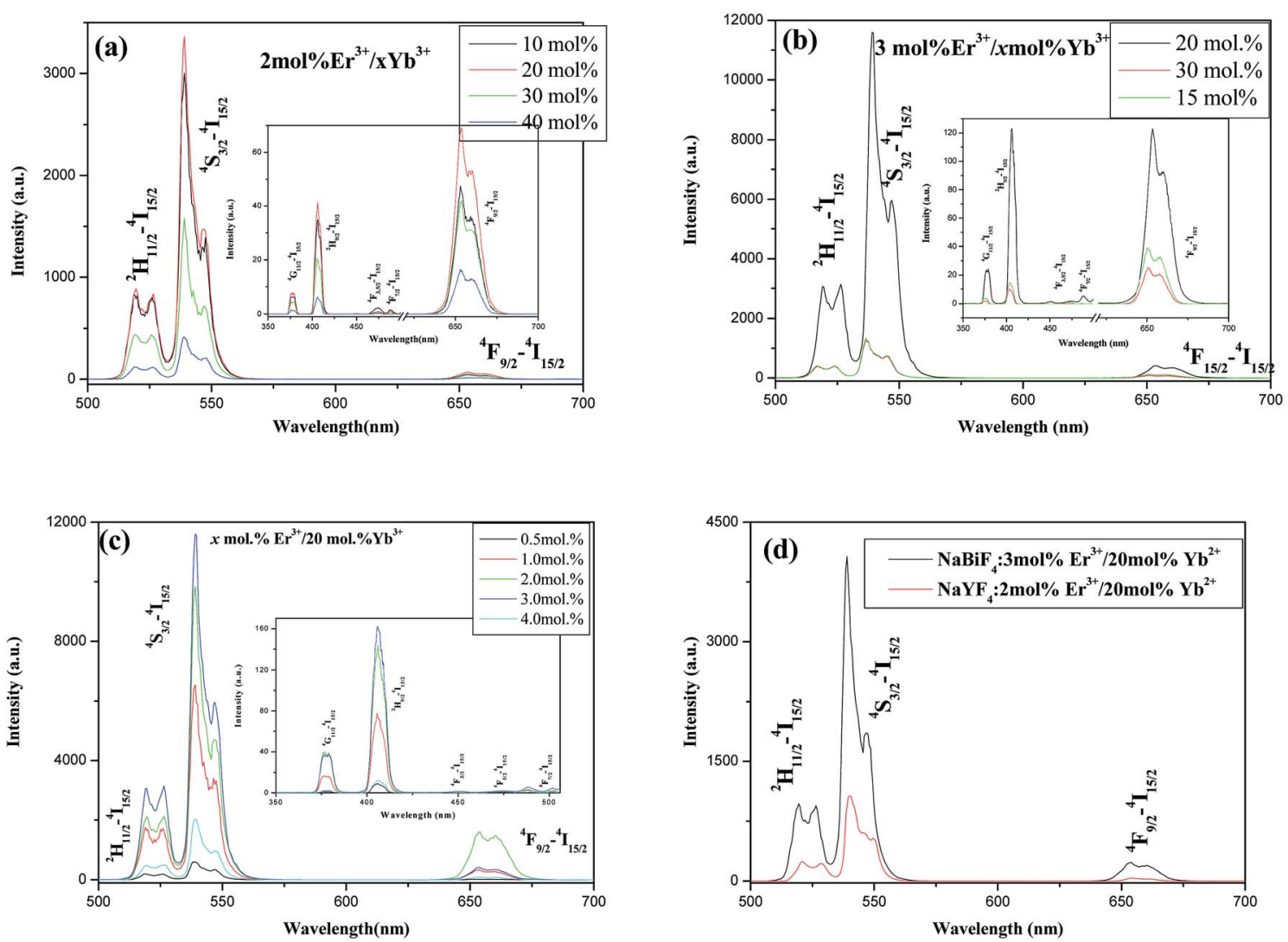

Fig. 7 The UC emission spectra of the $\mathrm{h}-\mathrm{NaBiF}_{4}: \mathrm{Er}^{3+} / \mathrm{Yb}^{3+}$ samples with different concentrations of $\mathrm{Er}^{3+}$ and $\mathrm{Yb}^{3+}:$ (a) $2 \mathrm{~mol} \% \mathrm{Er}^{3+} / x \mathrm{Yb}^{3+}(x=10$, 20, 30 and $40 \mathrm{~mol} \%$ ); (b) $3 \mathrm{~mol} \% \mathrm{Er}^{3+} / \mathrm{xYb}^{3+}$ ( $x=10,20$ and $30 \mathrm{~mol} \%$ ); (c) $x \mathrm{Er}^{3+} / 20 \mathrm{~mol} \% \mathrm{Yb}^{3+}(x=0.5,1,2,3$ and $4 \mathrm{~mol} \%$ ). 
UC emission to fall (Fig. 7a and b). In similar fashion in the samples with the constant $\mathrm{Yb}^{3+}$ doping $(20 \mathrm{~mol} \%$ ), the UC emission starts an upward trend as the $\mathrm{Er}^{3+}$ doping concentration increases from $0.5 \mathrm{~mol} \%$ to $2 \mathrm{~mol} \%$, arrives at a peak at 3.0 mol\% $\mathrm{Er}^{3+}$ doping concentration, then further increasing $\mathrm{Er}^{3+}$ concentration deduces to fall (see Fig. 7c). Thus, $\mathrm{NaBiF}_{4}: 3 \mathrm{~mol} \%$ $\mathrm{Er}^{3+} / 20 \mathrm{~mol} \% \mathrm{Yb}^{3+}$ sample exhibits the strongest UC emission, and possesses stronger green UC emission about 4 times than hexagonal $\mathrm{NaYF}_{4}: 2$ mol\% $\mathrm{Er}^{3+} / 20 \quad \mathrm{~mol} \% \mathrm{Yb}^{3+}$ nanocrystals under experimental condition (Fig. 7d). The size and morphology of the latter exhibit small conical hexagonal prisms with ca. $50 \mathrm{~nm}$ in diameter and $80-100 \mathrm{~nm}$ in length (see Fig. 7b and e in ref. 36 ).

Fig. 8 shows the UC emission spectra of $\mathrm{NaBiF}_{4}: 3 \mathrm{~mol}_{\mathrm{N} \mathrm{Er}^{3+}} /$ $20 \mathrm{~mol} \% \mathrm{Yb}^{3+}$ prepared under different conditions (including the reaction time, the reaction temperature, $\mathrm{NaF} / \mathrm{Ln}$ and $\mathrm{NH}_{4} \mathrm{NO}_{3} / \mathrm{Ln}$ molar ratio). It can be seen that the UC emissions are similar in the line, and the only difference between these bands are their intensities. From the figure plugged in Fig. 8a, the as-obtained sample at the NaF/Ln molar ratio of 5 has the highest UC emission intensity, and the strong green emission can be observed under several $\mathrm{mW} 980 \mathrm{~nm}$ excitation. The samples prepared at the $\mathrm{NaF} / \mathrm{Ln}$ molar ratio of 3 including c$\mathrm{BiF}_{3}$ and $\mathrm{t}-\mathrm{BiOF}$ possess the lowest UC intensity, whereas the $\mathrm{NaF} / \mathrm{Ln}$ molar ratio of 4 leads to the formation of $\mathrm{h}-\mathrm{NaBiF}_{4}$, thus substantially improving the intensity of UC emission. The resulting samples at the $\mathrm{NaF} / \mathrm{Ln}$ molar ratio of 5,6 , and 8 exhibit prism with the almost large diameter $(c a .0 .8 \mu \mathrm{m})$, their mean lengths become short. Similar to the hexagonal $\mathrm{NaYF}_{4}: 2 \mathrm{~mol} \%$
$\mathrm{Er}^{3+} / 20 \mathrm{~mol} \% \mathrm{Yb}^{3+}$, the green UC emission gradually decreased as the NaF/Ln molar ratio increased from 5 through 6 to 8, that is to say, the larger the length of the prism is, the stronger the UC emission is (see Fig. 3 and Table 1).

In addition, the change of the $\mathrm{NH}_{4} \mathrm{NO}_{3}$ usage amount can alter UC emission intensities of the samples (Fig. 8b). For the fixed $\mathrm{NaF} / \mathrm{Ln}$ molar ratio (5, 6 and 8, respectively), as $\mathrm{NH}_{4} \mathrm{NO}_{3} /$ Ln molar ratio gradually increases, the UC emission intensity of the corresponding sample also gradually reduces (plugged in Fig. 8b). This can be also related to the morphology and size of the sample. The increase of $\mathrm{NH}_{4} \mathrm{NO}_{3} / \mathrm{Ln}$ molar ratio deduces the length of the rod to shorten, thereby the UC emission of the corresponding sample also decreases.

With the enhancing reaction temperature and elongating reaction time, the UC emission became stronger and stronger (Fig. 8c and d). As mentioned above, the higher reaction temperature and longer reaction time are favorable for the transition from $\mathrm{m}-\mathrm{NH}_{4} \mathrm{BiF}_{4}$, t-BiOF to h-NaBiF${ }_{4}$ in the molten salt procedure and the proportion of $\mathrm{h}-\mathrm{NaBiF}_{4}$ increasing. Thus, the UC emission intensity of the samples is dramatically improved.

To determine the nature of the UC emission mechanisms responsible, we study the evolution of the intensities as a function of the pumping power for $\mathrm{NaBiF}_{4}: 3 \mathrm{~mol} \% \mathrm{Er}^{3+} / 20 \mathrm{~mol} \%$ $\mathrm{Yb}^{3+}$ sample. The UC emission intensity $I$ should scale as $P^{n}$ at low power limit (far from the saturation), where $n$ stands for the number of pumping phonons absorbed per UC phonon emitted and $P$ represents the pump power. ${ }^{48-51}$ A plot of $\ln I v s$. $\ln P$ yields a straight line with the slope $n$. Fig. 9 shows the plots for
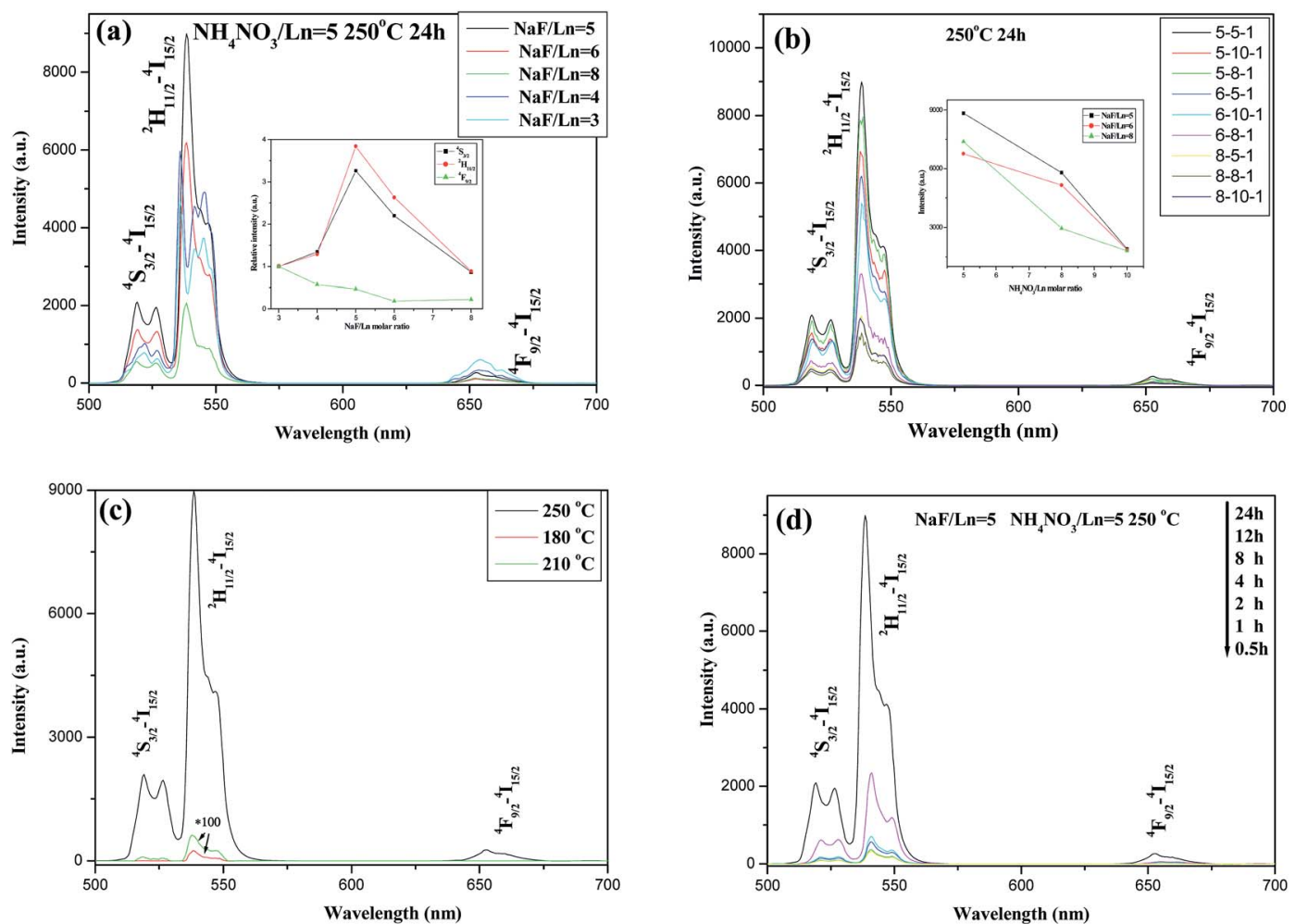

Fig. 8 The UC emission spectra of the $\mathrm{h}-\mathrm{NaBiF}_{4}: \mathrm{Er}^{3+} / \mathrm{Yb}^{3+}$ samples with different conditions. (a) Different $\mathrm{Na} / \mathrm{Ln} \mathrm{molar}$ ratios; (b) different $\mathrm{NH}_{4} \mathrm{NO}_{3} / \mathrm{Ln}$ molar ratios; (c) different reaction temperatures; (d) different reaction times. 


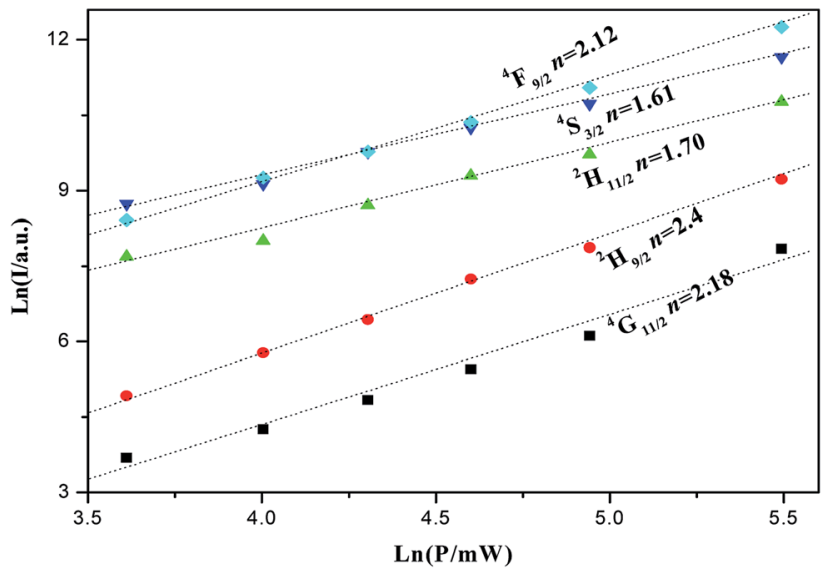

Fig. 9 Logarithmic plot of the integrated UC emission intensity of $\mathrm{h}$ $\mathrm{NaBiF}_{4}: 3 \mathrm{~mol} \% \mathrm{Er}^{3+} / 20 \mathrm{~mol} \% \mathrm{Yb}^{3+}$ sample at $295 \mathrm{~K}$ after $980 \mathrm{~nm}$ excitation.

${ }^{4} \mathrm{G}_{11 / 2},{ }^{2} \mathrm{H}_{9 / 2},{ }^{4} \mathrm{~F}_{9 / 2}{ }^{2} \mathrm{H}_{11 / 2},{ }^{4} \mathrm{~S}_{3 / 2},{ }^{4} \mathrm{~F}_{7 / 2}$ and emission. The slopes for ${ }^{2} \mathrm{H}_{11 / 2}$ and ${ }^{4} \mathrm{~S}_{3 / 2}$ and are 1.70 and 1.61 , respectively, which are close to 2 , indicating that two-phonon process deal with the UC mechanism responsible for populating these emitting levels, whereas the slope for ${ }^{4} \mathrm{~F}_{9 / 2},{ }^{4} \mathrm{G}_{11 / 2}$ and ${ }^{2} \mathrm{H}_{9 / 2}$ is 2.12, 2.4 and 2.18, respectively, implying that it is necessary to feed ${ }^{4} \mathrm{G}_{11 / 2}$ and ${ }^{2} \mathrm{H}_{9 / 2}$ level via three-phonon process. In addition, the slope for ${ }^{2} \mathrm{H}_{11 / 2}$ and ${ }^{4} G_{11 / 2}$ is relatively larger than that for ${ }^{4} S_{3 / 2}$ and ${ }^{2} H_{9 / 2}$, indicating that a faster growth of the former than the latter. This can be resulted from the thermal effect. As the pump power increases to high enough, the strong absorption brings forth the enhancement of the sample temperature at the irradiated region, generating the thermal effect and the fluorescence quenching. The small energy gap of ${ }^{2} \mathrm{H}_{11 / 2} /{ }^{4} \mathrm{~S}_{3 / 2}$ and ${ }^{4} \mathrm{G}_{11 / 2} /{ }^{2} \mathrm{H}_{9 / 2}$ pairs deduces more $\mathrm{Er}^{3+}$ ions to feed the ${ }^{2} \mathrm{H}_{11 / 2}$ and ${ }^{4} \mathrm{G}_{11 / 2}$ upper states via the thermal distribution as the pump power rise gradually. Therefore, the ${ }^{2} \mathrm{H}_{11 / 2}$ and ${ }^{4} \mathrm{G}_{11 / 2}$ state has a large slope $n$. In these samples, the predominant green emission in UC emission fluorescence indicates a larger population of the ${ }^{2} \mathrm{H}_{11 / 2} /{ }^{4} \mathrm{~S}_{3 / 2}$ level and a smaller population of the ${ }^{4} \mathrm{~F}_{9 / 2}$ level. In this case, the ${ }^{2} \mathrm{H}_{11 / 2}\left(\mathrm{Er}^{3+} 1\right)+{ }^{4} \mathrm{I}_{15 / 2}\left(\mathrm{Er}^{3+} 2\right) \rightarrow{ }^{4} \mathrm{I}_{9 / 2}\left(\mathrm{Er}^{3+} 1\right)+$ ${ }^{4} \mathrm{I}_{13 / 2}\left(\mathrm{Er}^{3+} 2\right)$ cross relaxation between $\mathrm{Er}^{3+}$ and the ${ }^{2} \mathrm{~F}_{7 / 2}\left(\mathrm{Yb}^{3+}\right)+$ $\mathrm{S}_{3 / 2}\left(\mathrm{Er}^{3+}\right) \rightarrow{ }^{2} \mathrm{~F}_{5 / 2}\left(\mathrm{Yb}^{3+}\right)+{ }^{4} \mathrm{I}_{13 / 2}\left(\mathrm{Er}^{3+}\right)^{9-12,48-51}$ energy back transfer becomes important. As a result, two NIR excitation photons are used to feed the ${ }^{4} \mathrm{I}_{13 / 2}$ state of $\mathrm{Er}^{3+}$. Since ${ }^{4} \mathrm{~F}_{9 / 2}$ level is populated from ${ }^{4} \mathrm{I}_{13 / 2}$ through energy transfer between $\mathrm{Er}^{3+}$ and $\mathrm{Yb}^{3+}$. Consequently, the ${ }^{4} \mathrm{~F}_{9 / 2}$ population, and thus red emission becomes a three-photons process.

To investigate UC emission mechanism and study the temperature dependence UC characteristics, the UC emission spectra of $\mathrm{NaBiF}_{4}: 3 \mathrm{~mol} \% \mathrm{Er}^{3+} / 20 \mathrm{~mol} \% \mathrm{Yb}^{3+}$ at different temperatures under the excitation wavelength of $980 \mathrm{~nm}$ were depicted in Fig. 11a and b. The intensity of the UC emission band attributed to the ${ }^{4} \mathrm{~S}_{3 / 2} \rightarrow{ }^{4} \mathrm{I}_{15 / 2}$ and ${ }^{2} \mathrm{H}_{9 / 2} \rightarrow{ }^{4} \mathrm{I}_{15 / 2}$ transition of $\mathrm{Er}^{3+}$ exhibits the same temperature dependent
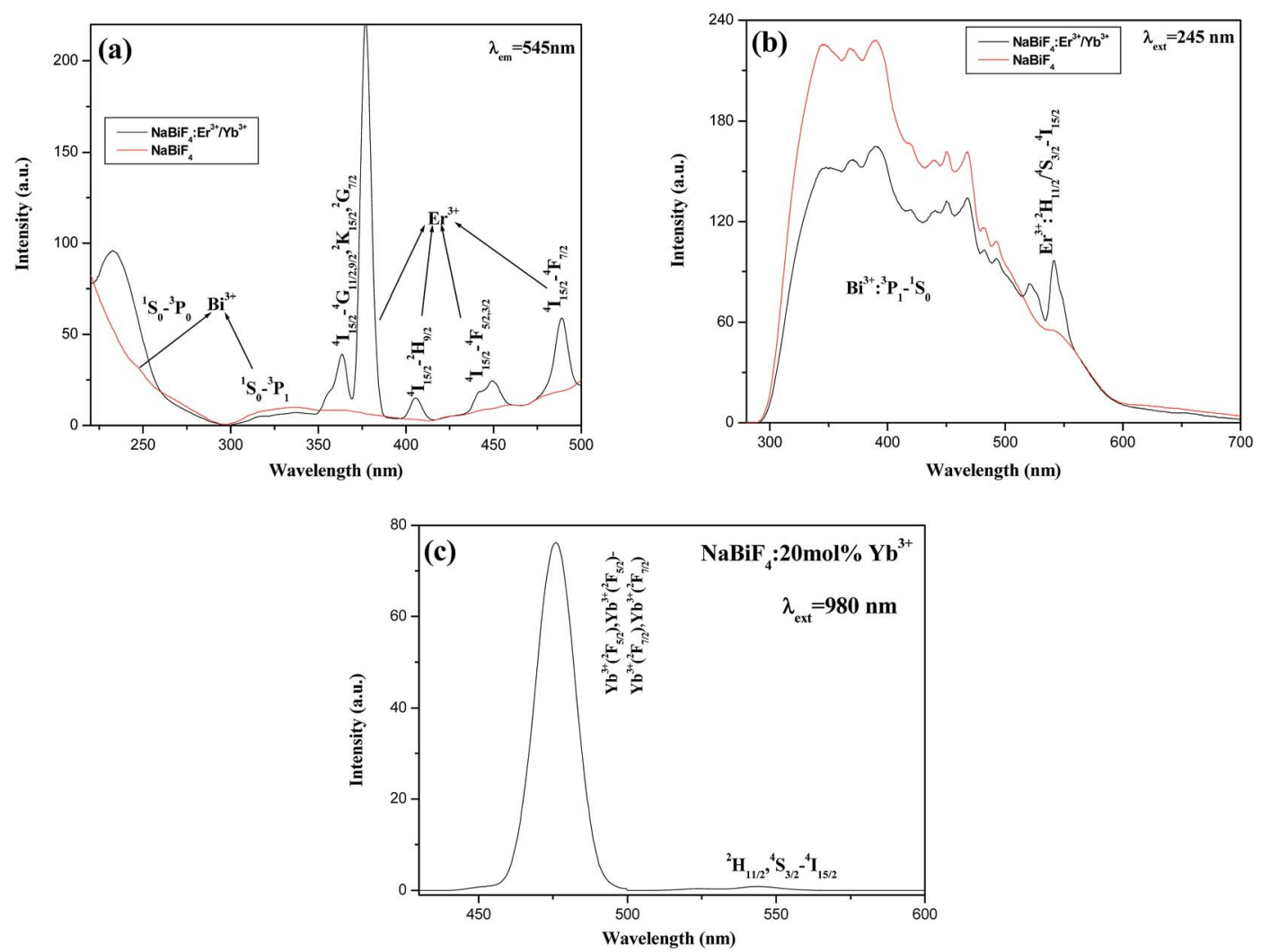

Fig. 10 The excitation spectra (a) and emission spectra (b) of $\mathrm{h}-\mathrm{NaBiF}_{4}: 3 \mathrm{~mol} \% \mathrm{Er}^{3+} / 20 \mathrm{~mol} \% \mathrm{Yb}^{3+}$ and pure $\mathrm{h}-\mathrm{NaBiF}_{4}$; (c) the cooperative $\mathrm{UC}$ spectra of $\mathrm{h}-\mathrm{NaBiF}_{4}: 20 \mathrm{~mol} \% \mathrm{Yb}^{3+}$. 

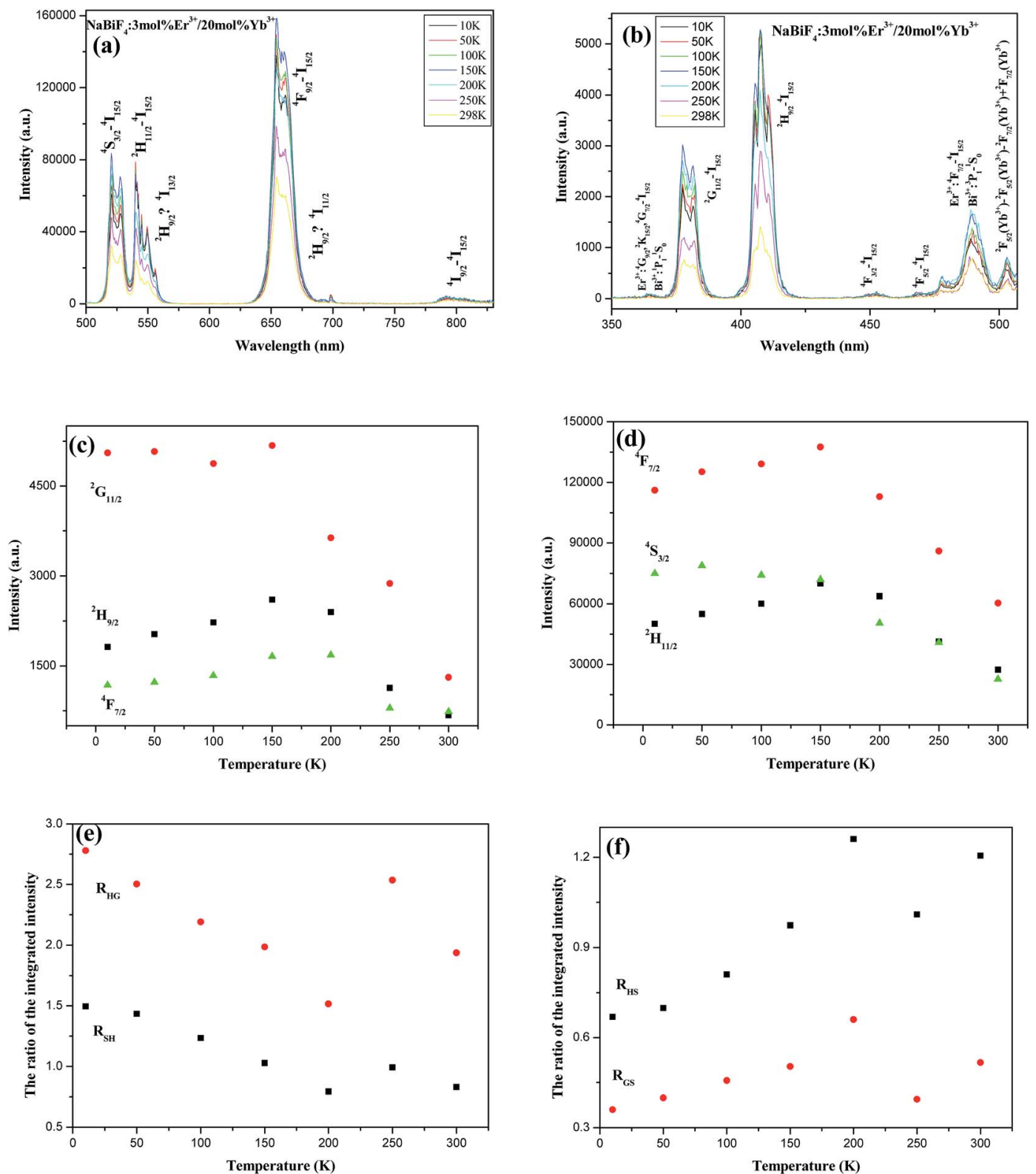

Fig. 11 ( $a$ and b) The UC emission spectra of the $\mathrm{NaBiF}_{4}: 3 \mathrm{~mol}^{2} \mathrm{Er}^{3+} / 20$ mol\% $\mathrm{Yb}^{3+}$ sample at different temperatures (the excitation wavelength is $980 \mathrm{~nm}$ ). (c and d) The UC emission intensity of $\mathrm{NaBiF}_{4}: 3 \mathrm{~mol} \% \mathrm{Er}^{3+} / 20 \mathrm{~mol} \% \mathrm{Yb}^{3+}$ sample as a function of the temperature; (e and f) the $R_{\mathrm{HS}}$ and $R_{\mathrm{GS}}$ of $\mathrm{NaBiF}_{4}: 3$ mol\% $\mathrm{Er}^{3+} / 20$ mol\% $\mathrm{Yb}^{3+}$ samples a function of the temperature.

behaviors, which may be resulted from that the population on the ${ }^{2} \mathrm{H}_{9 / 2}$ state of $\mathrm{Er}^{3+}$ can be excited from $\mathrm{S}_{3 / 2} /{ }^{2} \mathrm{H}_{11 / 2}$ state via the cross relaxation process of ${ }^{4} \mathrm{~S}_{3 / 2}\left(\mathrm{Er}^{3+} 1\right)+{ }^{4} \mathrm{I}_{13 / 2}\left(\mathrm{Er}^{3+} 2\right) \rightarrow$ ${ }^{2} \mathrm{H}_{9 / 2}\left(\mathrm{Er}^{3+} 1\right)+{ }^{4} \mathrm{I}_{15 / 2}\left(\mathrm{Er}^{3+} 2\right) \cdot{ }^{9-12}$ They stay at the same level with increasing temperature from 10 to $150 \mathrm{~K}$, then experience a significant downward trend. The other UC emissions exhibit another similar temperature dependent behavior. With decreasing temperature the emission intensities increase initially, reach a maximum at $150 \mathrm{~K}$, and then decrease (Fig. 11c). The reduction in the emission can be resulted from the decrease in resonant transfer because of the thermal depopulation of the higher-energy ${ }^{4} \mathrm{I}_{11 / 2} \mathrm{Er}^{3+}$ levels, which has a resonant match with the ${ }^{4} \mathrm{~F}_{7 / 2}$ level. The decrease of emission intensity can be originated from the temperature dependence of the multi-phonon de-excitation of the ${ }^{4} \mathrm{~S}_{3 / 2}\left({ }^{2} \mathrm{H}_{11 / 2}\right)$ and ${ }^{4} \mathrm{~F}_{9 / 2}$ level. Since it is most likely for a relatively tightly coupled pair to transfer to a single ion is and such pairs have the probability to relax back to ${ }^{4} \mathrm{I}_{J}$ levels again, the UC fluorescence quenching takes place. The fluorescence quenching becomes more effective than there occurs for the excitation into ${ }^{4} \mathrm{~F}_{7 / 2}$ of $\mathrm{Er}^{3+}$ aggravating the fluorescence quenching with increasing temperature. For ${ }^{4} \mathrm{~F}_{7 / 2}$, the emissions originating mainly from relatively isolated ions cause to reduce rate relaxation rate of ion-pair and to decrease the UC emission. ${ }^{49-54}$

In order to better understand the temperature-dependent behavior, $R_{\mathrm{HS}}$ (the ratio of ${ }^{2} \mathrm{H}_{11 / 2} \rightarrow{ }^{4} \mathrm{I}_{15 / 2}$ to ${ }^{4} \mathrm{~S}_{3 / 2} \rightarrow{ }^{4} \mathrm{I}_{15 / 2}$ ) and $R_{\mathrm{GH}}$ (the ratio of ${ }^{4} \mathrm{G}_{11 / 2} \rightarrow{ }^{4} \mathrm{I}_{15 / 2}$ to ${ }^{2} \mathrm{H}_{9 / 2} \rightarrow{ }^{4} \mathrm{I}_{15 / 2}$ ) as a function of temperature are shown as Fig. 11d, respectively. 
$R_{\mathrm{HS}}$ and $R_{\mathrm{GH}}$ possess the same temperature dependence characteristics. $R_{\mathrm{HS}}$ and $R_{\mathrm{GH}}$ firstly increase as the temperature enhances from $10 \mathrm{~K}$ to $200 \mathrm{~K}$, then have a downward trend and hit rock bottom when the temperature increases to $250 \mathrm{~K}$, finally recover to have an upward trend. Such phenomenon that the decreasing trend at $200-250 \mathrm{~K}$ indicates that there must be some additional UC channel energy transfers are involved with $\mathrm{Yb}^{3+}$ cooperative UC followed by the energy transfer to $\mathrm{Bi}^{3+}$, and the nonradiative energy transfer from the excited levels of $\mathrm{Er}^{3+}$ to the ${ }^{3} \mathrm{P}_{1}$ manifold of $\mathrm{Bi}^{3+}$, followed by energy back energy to another manifolds of $\mathrm{Er}^{3+}$.

To authenticate the existence of energy transfer process between $\mathrm{Bi}^{3+}$ and $\mathrm{Er}^{3+}$, the excitation and emission spectra of $\mathrm{NaBiF}_{4}: 3 \mathrm{~mol} \% \mathrm{Er}^{3+} / 20 \mathrm{~mol} \% \mathrm{Yb}^{3+}$ and $\mathrm{NaBiF}_{4}$ have been measured and are depicted in Fig. 10. The excitation and emission wavelengths are 245 and $545 \mathrm{~nm}$, respectively. In the excitation spectra (Fig. 10a), there exists broad absorption bands owing to $\mathrm{Bi}^{3+}$ ions, ${ }^{15-19}$ while some emission bands due to the transitions of $\mathrm{Er}^{3+}$ ions are also observed in the emission spectra (Fig. 10b), ${ }^{1-12}$ implying that the interaction between $\mathrm{Bi}^{3+}$ and $\mathrm{Er}^{3+}$ takes place. In addition, the anti-Stokes UC fluorescence spectra of $\mathrm{NaBiF}_{4}: 20 \mathrm{~mol} \% \mathrm{Yb}^{3+}$ samples under $980 \mathrm{~nm}$ excitation at room temperature was also shown in Fig. 10c. The observed anti-Stokes in the range of $470-510 \mathrm{~nm}$ is believed to be cooperative UC causing by the simultaneous radiative relaxation of the excited $\mathrm{Yb}^{3+}-\mathrm{Yb}^{3+}$ pairs accompanied by the emission of a visible photon in the expression ${ }^{2} \mathrm{~F}_{5 / 2}\left(\mathrm{Yb}^{3+}\right)-{ }^{2} \mathrm{~F}_{5 / 2}\left(\mathrm{Yb}^{3+}\right) \rightarrow$ ${ }^{2} \mathrm{~F}_{7 / 2}\left(\mathrm{Yb}^{3+}\right)+{ }^{2} \mathrm{~F}_{7 / 2}\left(\mathrm{Yb}^{3+}\right)+h \nu^{45-47}$ and the emission from the ${ }^{3} \mathrm{P}_{1}$ excited state to the ${ }^{1} \mathrm{~S}_{0}$ ground state of $\mathrm{Bi}^{3+} \cdot{ }^{\mathbf{1 4 , 1 5 , 2 2}}$

To further validate the rationality of the energy transfer from $\mathrm{Bi}^{3+}$ to $\mathrm{Er}^{3+}$, the UC emission spectra of $\mathrm{NaYF}_{4}: 2 \mathrm{~mol} \% \mathrm{Er}^{3+} / 20$ $\mathrm{mol} \% \mathrm{Yb}^{3+}$ at different temperatures and the emission decay curves of ${ }^{4} \mathrm{~S}_{3 / 2} \rightarrow{ }^{4} \mathrm{I}_{15 / 2}$ transition in h-NaBiF $4: 3 \mathrm{~mol} \% \mathrm{Er}^{3+} / 20$ mol\% $\mathrm{Yb}^{3+}$ (the former) and h-NaYF $4: 2 \mathrm{~mol} \% \mathrm{Er}^{3+} / 20 \mathrm{~mol} \%$ $\mathrm{Yb}^{3+}$ (the latter) were measured under the excitation wavelength of $980 \mathrm{~nm}$, as shown in Fig. 12. Both h-NaBiF 4 and h-NaYF 4 belong to the hexagonal system with the same space group $P \overline{3}$, and the crystal cell parameter of h- $\mathrm{NaBiF}_{4}(a=6.144 \AA, c=$ $3.721 \AA)^{32}$ is slightly larger than that of h-NaYF $4(a=5.96 \AA, c=$ $3.53 \AA) .{ }^{55}$ In the same doping concentration, the mean distance between $\mathrm{Yb}^{3+}$ ions in the former is larger than that in the latter. The cooperative UC intensity depends upon the shortest distances between $\mathrm{Yb}^{3+}$ ions, and the smaller the distance between $\mathrm{Yb}^{3+}$ ions, the stronger the cooperative UC emission, ${ }^{\mathbf{4 5 - 4 7}}$ thereby, the cooperative UC intensity of the former is weaker than that of the latter. As a matter of fact, the UC emission intensity of the former is stronger than that of the latter (see figure). It is suggested that there exists the energy transfer between $\mathrm{Er}^{3+}$ ion or $\mathrm{Yb}^{3+}$ ion and $\mathrm{Bi}^{3+}$ ion in $\mathrm{h}-\mathrm{NaBiF}_{4}: 3 \mathrm{~mol} \% \mathrm{Er}^{3+} / 20 \mathrm{~mol} \% \mathrm{Yb}^{3+}$ sample. In addition, the decay curves of both the samples could be well fitted into a single exponential function (Fig. 12a). It is obvious that the lifetime of the ${ }^{4} \mathrm{~S}_{3 / 2}$ state in the former $(267 \mu \mathrm{s})$ is longer than that in the latter $(147 \mu \mathrm{s})$. Moreover, the former exhibits longer rise and delay times than the latter. This further affirms the existence of energy transfer between $\mathrm{Er}^{3+}$ ion and $\mathrm{Bi}^{3+}$ ions in h- $\mathrm{NaBiF}_{4}: 3 \mathrm{~mol} \% \mathrm{Er}^{3+} / 20 \mathrm{~mol} \% \mathrm{Yb}^{3+}$.

Based on the above analysis, the energy diagram showing the proposed UC emission mechanism and energy transfer process in $\mathrm{NaBiF}_{4}: \mathrm{Er}^{3+} / \mathrm{Yb}^{3+}$ materials was depicted in Fig. 13. The initially increasing $\mathrm{Yb}^{3+}$ doping rapidly promotes the rate of energy transfer from $\mathrm{Yb}^{3+}$ to $\mathrm{Er}^{3+}$, enhancing the population on the green-emitting participating ${ }^{4} \mathrm{~F}_{7 / 2}$ and red-emitting participating ${ }^{4} \mathrm{I}_{11 / 2}$ manifolds, which results in the improvement of the UC emission. Too high $\mathrm{Yb}^{3+}$ doping concentration induces an efficient energy back-transfer process ${ }^{4} \mathrm{~F}_{7 / 2}\left(\mathrm{Er}^{3+}\right)+{ }^{2} \mathrm{~F}_{5 / 2}\left(\mathrm{Yb}^{3+}\right) \rightarrow$ ${ }^{4} \mathrm{I}_{11 / 2}\left(\mathrm{Er}^{3+}\right)+{ }^{2} \mathrm{~F}_{5 / 2}\left(\mathrm{Yb}^{3+}\right)^{9-12}$ and ${ }^{4} \mathrm{~F}_{9 / 2}\left(\mathrm{Er}^{3+}\right)+{ }^{2} \mathrm{~F}_{5 / 2}\left(\mathrm{Yb}^{3+}\right) \rightarrow$ ${ }^{4} \mathrm{I}_{13 / 2}\left(\mathrm{Er}^{3+}\right)+{ }^{2} \mathrm{~F}_{5 / 2}\left(\mathrm{Yb}^{3+}\right),{ }^{9-12}$ causing the decrease of the population on the ${ }^{4} \mathrm{~F}_{7 / 2},{ }^{4} \mathrm{I}_{11 / 2},{ }^{2} \mathrm{H}_{11 / 2} /{ }^{4} \mathrm{~S}_{3 / 2}$ and ${ }^{4} \mathrm{~F}_{9 / 2}$ manifold, accordingly the green UC emission and red one both experiences a significant downward trend. At low $\mathrm{Er}^{3+}$ doping concentration, there are not enough $\mathrm{Er}^{3+}$ ions to be populated or excited. The increase of $\mathrm{Er}^{3+}$ concentration makes the average distance between $\mathrm{Er}^{3+}$ ions shrink and the interaction between ions intensifies. This induces the population on the ${ }^{4} \mathrm{~F}_{7 / 2},{ }^{4} \mathrm{I}_{11 / 2},{ }^{2} \mathrm{H}_{11 / 2},{ }^{4} \mathrm{~S}_{3 / 2}$ and ${ }^{4} \mathrm{~F}_{9 / 2}$ states increase, and gives rise to the increase of the population on the green and red-emitting manifolds, thus, the red and green emission experiences an upward trend. When the $\mathrm{Er}^{3+}$ doping concentration achieves a certain crisis, the average interaction distance between $\mathrm{Er}^{3+}$ and $\mathrm{Yb}^{3+}$ is beyond the critical distance of the energy back transfer ${ }^{4} \mathrm{I}_{11 / 2}\left(\mathrm{Er}^{3+}\right)+{ }^{2} \mathrm{~F}_{7 / 2}\left(\mathrm{Yb}^{3+}\right) \rightarrow{ }^{4} \mathrm{I}_{15 / 2}\left(\mathrm{Er}^{3+}\right)+$
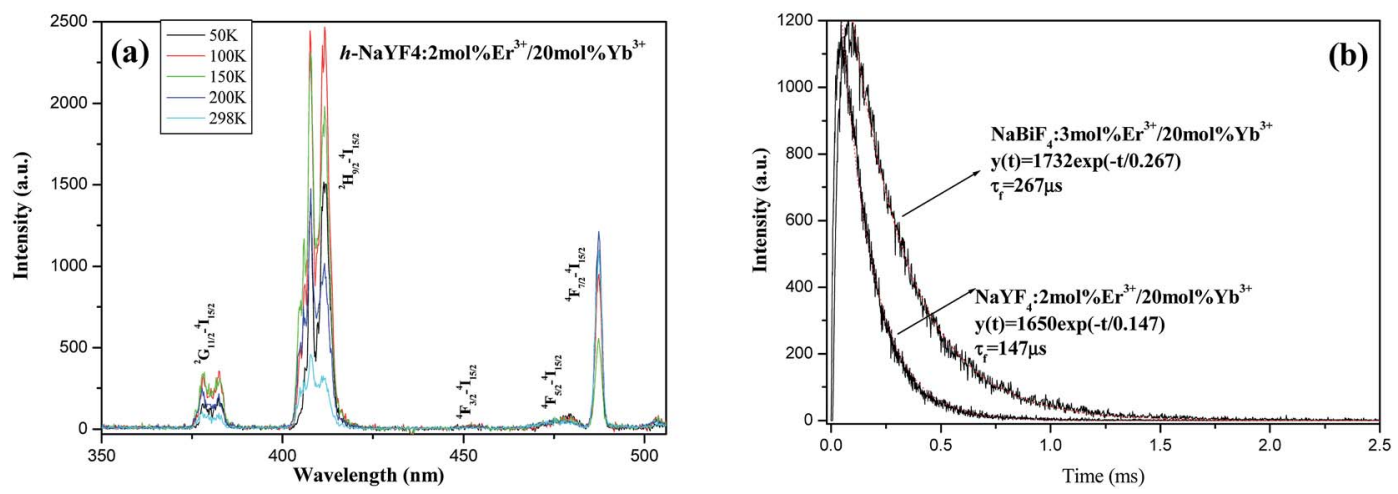

Fig. 12 (a) The UC emission spectra of the $\mathrm{NaYF}_{4}: 2$ mol\% $\mathrm{Er}^{3+} / 20$ mol\% $\mathrm{Yb}^{3+}$ sample at different temperatures (the excitation wavelength is $980 \mathrm{~nm}$ ). (b) The decay curves UC emission intensity of $532 \mathrm{~nm}$ of $\mathrm{NaBiF}_{4}: 3 \mathrm{~mol} \% \mathrm{Er}^{3+} / 20 \mathrm{~mol}^{2} \mathrm{Yb}^{3+} \mathrm{and} \mathrm{NaYF}_{4}: 2 \mathrm{~mol}^{2} \mathrm{Er}^{3+} / 20 \mathrm{~mol}^{3} \mathrm{Yb}^{3+}$ samples. 


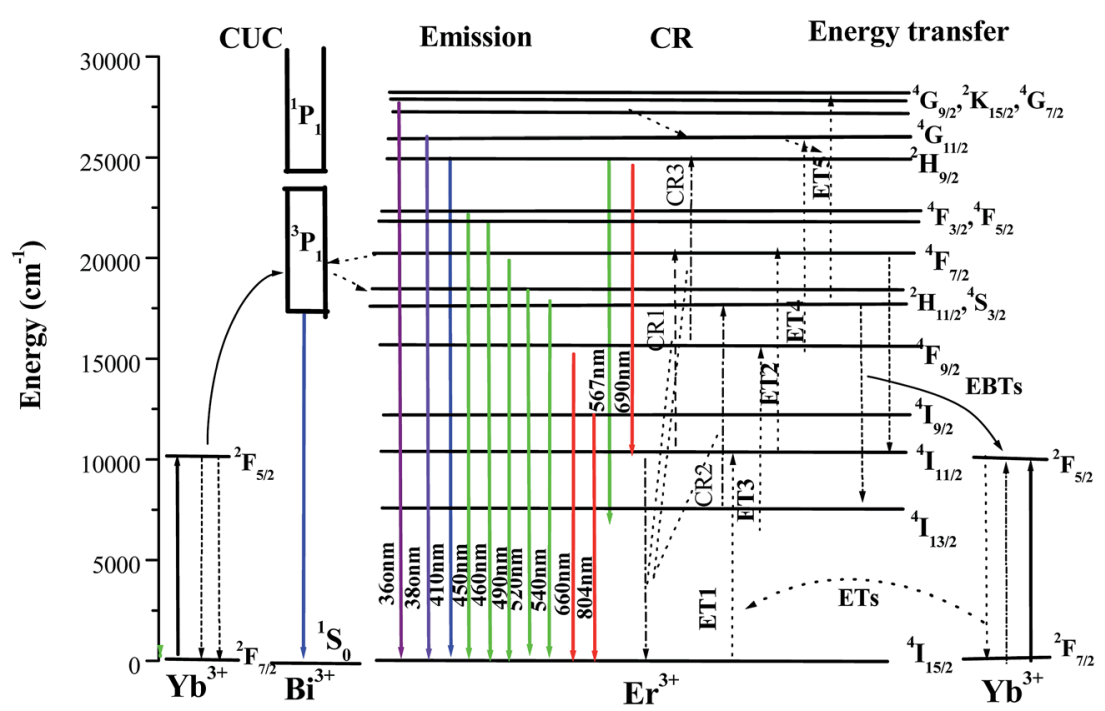

Fig. 13 Schematic energy level diagrams of $\mathrm{Bi}^{3+}, \mathrm{Er}^{3+}$ and $\mathrm{Yb}^{3+}$ ions as well as the proposed energy transfer of $\mathrm{NaBiF}_{4}: \mathrm{Er}^{3+} / \mathrm{Yb}^{3+} \mathrm{under}$ excitation of $980 \mathrm{~nm}$.

${ }^{2} \mathrm{~F}_{5 / 2}\left(\mathrm{Yb}^{3+}\right)(\mathrm{EBT}),{ }^{9-12}$ which leads to a considerate drop the population on the red-emitting ${ }^{4} \mathrm{~F}_{9 / 2}$ manifold and the green-emitting ${ }^{2} \mathrm{H}_{11 / 2} /{ }^{4} \mathrm{~S}_{3 / 2}$ and violet emitting ${ }^{4} \mathrm{G}_{11 / 2}$ manifold. As a consequence, the intensity of the visible emission abruptly falls off, while the green one quickly rises. Obviously, 4 mol\% exceeds the critical concentration, whereas $3 \mathrm{~mol} \%$ is below this threshold.

\section{Conclusions}

The hexagonal $\mathrm{NaBiYF}_{4}: \mathrm{Er}^{3+} / \mathrm{Yb}^{3+}$ micro-/nanocrystals were synthesized via low-temperature molten-salt method in $\mathrm{NH}_{4} \mathrm{NO}_{3}$ flux. The influences of the reaction time, the reaction temperature, the content of $\mathrm{NaF}$ and $\mathrm{NH}_{4} \mathrm{NO}_{3}$ on the crystal phase of the resulting products were studied at length. This research also investigates and discusses in detail the effects of shapes, sizes, doping concentration of $\mathrm{Er}^{3+}$ and $\mathrm{Yb}^{3+}$, the pumping power and the temperature on the UC emission of $\mathrm{NaBiYF}_{4}: \mathrm{Er}^{3+} / \mathrm{Yb}^{3+}$ micro-/nanocrystals. The results show that the $\mathrm{NaBiF}_{4}: 3 \mathrm{~mol} \% \mathrm{Er}^{3+} / 20 \mathrm{~mol} \% \mathrm{Yb}^{3+}$ sample exhibits the strongest UC emission and can be comparable to the most efficient UC hexagonal $\mathrm{NaYF}_{4}: \mathrm{Er}^{3+} / \mathrm{Yb}^{3+}$ micro-/nanocrystals. Two-phonon process takes responsibility to populate ${ }^{4} \mathrm{~S}_{3 / 2}{ }^{2} \mathrm{H}_{11 / 2}$ of $\mathrm{Er}^{3+}$, whist the ${ }^{4} \mathrm{~F}_{9 / 2}$ is involved in a three-photon process. The energy transfer between the excited levels of $\mathrm{Er}^{3+}$ and the ${ }^{3} \mathrm{P}_{1}$ manifold of $\mathrm{Bi}^{3+}$ and cooperative $\mathrm{UC}$ of $\mathrm{Yb}^{3+}$ are favorable to improve upconversion emission of $\mathrm{Er}^{3+}$. This work is significant not only to provide one novel synthesis method of Bi-based fluoride UC materials but also for the better understanding of their essential UC emission mechanisms (particularly the energy transfer from $\mathrm{Bi}^{3+}$ to $\mathrm{Er}^{3+}$ ).

\section{Conflicts of interest}

There are no conflicts to declare.

\section{Acknowledgements}

This work was supported by the National Natural Science Foundation of China (61204003), Train Object Program of Jiangxi Province Young Scientists, Natural Science Foundation of Jiangxi Province (No. 20142BAB206011 and 2011BAB206029) and Luodi program of Jiangxi Province (No. KJLD13030), respectively.

\section{References}

1 B. Zhou, B. Y. Shi and X. G. Liu, Nat. Nanotechnol., 2015, 10, 924.

2 M. Haase and H. Schäfer, Angew. Chem., Int. Ed., 2011, 50, 5808.

3 S. Y. Han, R. R. Deng, X. J. Xie and X. G. Liu, Angew. Chem., Int. Ed., 2014, 53, 2.

4 G. Y. Chen, J. W. Seo, C. H. Yang and P. N. Prasad, Chem. Soc. Rev., 2013, 242, 8304.

5 W. F. yang, X. Y. Li, D. Z. Chi, H. J. Zhang and X. G. Liu, J. Nanotechnol., 2015, 25, 482001.

6 X. M. Li, F. Zhang and D. Y. Zhao, Chem. Soc. Rev., 2015, 44, 1346.

7 X. D. Wang, O. S. Wolfbeis and R. J. Meier, Chem. Soc. Rev., 2013, 42, 7834.

8 G. Y. Chen, H. L. Qiu, P. N. Parasad and X. Y. Chen, Chem. Rev., 2014, 110, 5161.

9 W. Zhang, P. Huang, E. Ma, H. M. Zhu and X. Y. Chen, Chem. Soc. Rev., 2015, 44, 1379.

10 H. Dong, L. D. Sun and C. H. Yan, Nanoscale, 2013, 5, 5657. 11 L. P. Tu, X. M. Liu, F. Wu and H. Zhang, Chem. Soc. Rev., 2015, 44, 1331.

12 H. Dong, L. D. Sun and C. H. Yan, Chem. Soc. Rev., 2015, 44, 1608.

13 J. F. Suyver, J. Grimm, M. K. van Veen, D. Biner, K. W. Krämer and H. U. Güdel, J. Lumin., 2006, 117, 1. 
14 P. Boutinaud, Inorg. Chem., 2013, 52, 6028.

15 R. H. P. Awater and P. Dorenbos, J. Lumin., 2017, 184, 221.

16 G. J. Gao, M. Y. Peng and L. Wondraczek, J. Mater. Chem. C, 2014, 2, 8085.

17 R. V. Yadav, R. S. Yadav, A. Bahadur and A. K. Singh, Inorg. Chem., 2016, 55, 10928.

18 A. Urbina-Frías, T. López-Luke, H. Desirena, P. Salas, A. Terres-Casatro and E. De la Rosa, Opt. Mater, , 2015, 48, 92.

19 M. Z. Yang, Y. Sui, S. C. Lü, M. J. Wang, X. J. Wang, M. H. Wu, Y. Wang, Y. T. Q. Lü and W. F. Liu, J. Alloys Compd., 2011, 509, 8590.

20 J. P. Fu, R. Pang, Y. L. Jia, W. Z. Sun, L. H. Jiang, S. Zhang and C. Y. Li, J. Lumin., 2017, 181, 240.

21 P. P. Lei, P. Zhang, S. Yao, S. Y. Song, L. L. Dong, X. Liu, X. L. Liu, K. M. Du, J. Feng and H. J. Zhang, ACS Appl. Mater. Interfaces, 2016, 8, 27490.

22 N. Niu, F. He, S. L. Gai, C. X. Li, H. Huang and P. P. Yang, J. Mater. Chem., 2012, 22, 21613.

23 K. J. Chong, T. Hirai, S. Hashimoto and N. Ohno, J. Lumin., 2017, 122-123, 149.

24 A. Escudero, E. Moretti and M. Ocaña, CrystEngComm, 2014, 16, 3274 .

25 J. M. Zhao, H. L. Pan, X. He, Y. S. Wang, L. Gu, Y. S. Hu, L. Q. Chen, H. Z. Liu and S. Dai, Nanoscale, 2013, 5, 518.

26 W. B. Niu, S. L. Wu, S. F. Zhang, J. Li and L. Li, Dalton Trans., 2011, 40, 3305.

27 H. X. Mai, Y. W. Zhang, L. D. Sun and C. H. Yan, J. Phys. Chem. C, 2007, 111, 13721.

28 W. J. Yao, Q. Y. Tian, Z. H. Wu, S. Y. Cui, Z. G. Dai and W. Wu, J. Mater. Chem. C, 2016, 4, 6327.

29 H. L. in, D. K. Xu, A. M. Li, D. D. Teng, S. H. Yang and Y. L. Zhang, J. Mater. Chem. C, 2015, 3, 11754.

30 D. T. Klier and M. U. Kumke, J. Mater. Chem. C, 2015, 3, 11228.

31 P. P. Lei, R. An, S. Yao, Q. S. Wang, L. L. Dong, K. M. Du, J. Feng and H. J. Zhang, Adv. Mater., 2017, 22, 00505.

32 P. Fedorov, et al., Russ. J. Inorg. Chem., 1979, 24, 157.

33 B. Shao, Z. W. Yang, Y. D. Wang, J. Li, J. Z. Yang, J. B. Qiu and Z. G. Song, ACS Appl. Mater. Interfaces, 2015, 7, 25211.

34 J. Y. Liao, Z. W. Yang, H. J. Wu, D. Yan, J. B. Qiu, Z. G. Qiu, Y. Yang, D. C. Zhou and Z. Y. Yin, J. Mater. Chem. C, 2013, 1, 6541.
35 S. L. Gai, C. X. Li, P. P. Yang and J. Lin, Chem. Rev., 2014, 114, 2343.

36 X. Y. Huang, G. H. Hu, Q. J. Xu, X. X. Li and Q. M. Yu, J. Alloys Compd., 2014, 616, 652.

37 X. Y. Huang, Opt. Mater. Express, 2014, 4, 2381.

38 X. Y. Huang, L. Jiang, X. X. Li and A. Q. He, J. Alloys Compd., 2017, 6721, 374.

39 X. Y. Huang, Opt. Mater., 2015, 50, 81.

40 D. M. Mathews, R. B. Ambekar, K. A. Tyagi and J. Köhler, J. Alloys Compd., 2004, 377, 162-166.

41 F. Zhang, Y. Wan, T. Yu, F. Q. Zhang, Y. F. Shi, S. H. Xie, Y. G. Li, L. Xu, B. Tu and D. Y. Zhao, Angew. Chem., Int. Ed., 2007, 46, 7976.

42 A. Naduviledathu Raj, T. Rinkel and M. Hasse, Chem. Mater., 2014, 26, 5689.

43 M. Y. Ding, C. H. Lu, L. H. Cao, Y. R. Ni and Z. Z. Xu, CrystEngComm, 2014, 4, 29165.

44 X. Qu, H. Song, X. Bai, G. Pan, B. Dong, H. Zhao, F. Wang and R. Qin, Inorg. Chem., 2008, 47, 9654.

45 E. Nakazawa and S. Shionoya, Phys. Rev. Lett., 1970, 25, 1710.

46 D. G. Deng, S. Q. Xu, R. Q. Bao, S. L. Zhao, B. L. Wang, H. P. Wang and H. D. Ju, J. Phys. D: Appl. Phys., 2009, 42, 105111.

47 X. Y. Huang, Chin. Opt. Lett., 2010, 8, 780.

48 M. Pollnau, D. R. Gamelin, S. R. Lüthi, H. U. Güdel and M. P. Hehlen, Phys. Rev. B: Condens. Matter Mater. Phys., 2000, 61, 3337.

49 F. Vetrone, J. C. Boyer, J. A. Capobianco, A. Speghini and M. Bettinll, J. Appl. Phys., 2004, 96, 661.

50 J. F. Suyver, A. Aebisher, S. García-Revilla, P. Gerner and H. U. Güdel, Phys. Rev. B: Condens. Matter Mater. Phys., 2005, 71, 125123.

51 J. P. van der Ziel, F. W. Ostermayer Jr and L. G. Van Uitert, Phys. Rev. B: Condens. Matter Mater. Phys., 1970, 2, 4432.

52 K. Y. Wu, J. B. Cui, X. Kong and Y. J. Wang, J. Appl. Phys., 2011, 110, 053510.

53 A. M. Pires and O. A. Serra, J. Appl. Phys., 2005, 98, 063529.

54 D. D. Li, Q. Y. Shao, Y. Yan and J. J. Jiang, J. Phys. Chem. C, 2014, 118, 22807.

55 Y. S. Liu, H. M. Zhu, R. F. Li, L. Q. Liu and X. Y. Chen, Angew. Chem., Int. Ed., 2013, 52, 1128. 